\title{
Arcabouço estratigráfico da Formação Sergi (Jurássico Superior) na Bacia de Almada, Bahia
}

\author{
Felipe Adegas $^{1 *}$, Claiton M. S. Scherer ${ }^{2}$, Christian Born ${ }^{3}$
}

\begin{abstract}
Resumo O presente trabalho analisou os depósitos fluviais e eólicos da Formação Sergi (seção pré-rifte) na Bacia de Almada, com o objetivo de fornecer um arcabouço estratigráfico deste intervalo, baseado em conceitos da estratigrafia de sequências. Esta unidade foi depositada em uma ampla bacia intracratônica durante o Jurássico Superior e o Cretáceo Inferior. Com a utilização de dados de campo e de poços, foi possível individualizar três sequências deposicionais internas à Formação Sergi, sendo as duas basais correspondentes ao intervalo da Formação Sergi e a superior abrangendo o topo das Formações Sergi e Itaípe. O critério utilizado para definição deste arcabouço foi a mudança abrupta das associações de fácies ao longo das superfícies correlacionáveis na escala de bacia e nos poços, e a correlação regional com bacias adjacentes. A sequência I é composta pela associação de fácies do cinturão de canais fluviais entrelaçados, com paleocorrentes para NE e por associações de fácies de dunas e interdunas eólicas com paleocorrentes para SW. A sequência II inclui a associação de fácies do cinturão de canais fluviais entrelaçados, com paleocorrentes para NE. Ainda, a sequência III possui na base a associação das fácies de lençóis de areia eólicos e no topo a associação de fácies lacustre. O desenvolvimento das sequências deposicionais e de suas discordâncias limítrofes responde a variações na taxa acomodação (A)/suprimento sedimentar (S), induzidas por rearranjos tectônicos e climáticos na bacia.
\end{abstract}

Palavras-chave: Bacia de Almada; Formação Sergi; estratigrafia de sequências; interação flúvio-eólica.

\begin{abstract}
Stratigraphic framework of Sergi Formation (Upper Jurassic) in the Almada Basin, Bahia, Brazil. This study analyzed the fluvial and aeolian deposits of Sergi Formation (pre-rift section) in the Almada Basin, aiming at supplying a stratigraphic framework for this interval, based on concepts of sequence stratigraphy. Sergi Formation was deposited in a wide intracratonic basin during the Neo-Jurassic and Eo-Cretaceous periods. By using outcrops and well data, it was possible to subdivide The Sergi Formation into three distinct depositional sequences. Sequences I and II correspond to the Sergi Formation lithostratigraphic interval and Sequence III encompasses the top of the Sergi Formation plus the Itaípe Formation. The criterion used to define this framework was the abrupt shift of the facies association along correlated surfaces in a basin scale, in well logs, and also in a regional correlation with adjacent basins. Sequence I is composed of braided fluvial channel belt facies association, with paleochannels flowing to the NW quadrant and by aeolian dunes and interdunes facies association, with paleocurrents indicating aeolian palaeodunes migrating to the SE quadrant. Sequence II is made up of braided fluvial channel belt facies association, with paleochannels flowing northeast. At its base, the Sequence III is composed of aeolian sand sheets facies association and at the top of lacustrine facies association. The development of these depositional sequences and their boundary surfaces is a consequence of variations in the rates of accommodation space (A)/ and sedimentary supply (B), which are triggered by tectonic rearrangements and climatic oscillations in the basin.
\end{abstract}

Keywords: Almada Basin; Sergi Formation; sequence stratigraphy; fluvio-aeolian interaction.

\section{INTRODUÇÃO A Formação Sergi acumu-} lou-se em uma grande bacia (depressão afro-brasileira) que cobria uma extensa área do nordeste brasileiro, estendendo-se inclusive ao continente africano, sendo constituída essencialmente por depósitos fluviais e eólicos (Küchle et al. 2011). A ampla ocorrência e espessura desta unidade, associada à alta permeabilidade e porosidade dos arenitos, confere-lhe o status de maior reservatório na Bacia do Recôncavo com um volume original de 362 milhões $\mathrm{m}^{3}$ de óleo in place (Scherer \& De Ros 2009, Bongiolo \& Scherer 2010).
Apesar dos depósitos flúvio-eólicos da Formação Sergi terem sido alvos de inúmeros estudos nas últimas décadas, foi somente no final da década de 1990 que se começou a examinar esta unidade sob a ótica da estratigrafia de sequências (Oliveira 2005, Scherer et al. 2007). Na Bacia de Almada, estudos que enfocam a faciologia e os controles da sedimentação neste intervalo são inexistentes. Em decorrência disso, os principais objetivos deste trabalho consistiram na identificação e no detalhamento das associações de fácies e na construção de um arcabouço estratigráfico de alta resolução

${ }^{1}$ Conselho Nacional de Desenvolvimento Científico e Tecnológico - CNPq, Programa de Pós-Graduação em Geociências na Universidade Federal do Rio Grande do Sul - UFRGS, Porto Alegre (RS), Brasil. E-mail: felipe_adegas@hotmail.com ${ }^{2}$ Instituto de Geociências, Universidade Federal do Rio Grande do Sul - UFRGS, Porto Alegre (RS), Brasil. E-mail: claiton.scherer@ufrgs.br ${ }^{3}$ Petrobras, Vitória (ES), Brasil. E-mail: cristão_geo@hotmail.com

*Autor correspondente 
para os depósitos flúvio-eólicos da Formação Sergi na Bacia de Almada. Como objetivos específicos deste trabalho podem-se citar: levantamento, descrição e interpretação faciológica de seções colunares; determinação dos padrões de paleocorrentes e discussão dos fatores controladores da ciclicidade na sedimentação.

A metodologia aplicada neste estudo fundamentou-se essencialmente em trabalhos de campo, nos quais procurou-se estudar as exposições possíveis da Formação Sergi na Bacia de Almada, localizadas a partir de fotografias aéreas e roteiros geológicos existentes (Netto \& Sanches 1991). Dependendo da qualidade da exposição, foram levantadas seções colunares com descrição, interpretação e associações de fácies. Somado a esses, foram analisados três poços estratigráficos com perfis de raios gama. Por meio da elaboração de seções geológicas, foram correlacionadas informações de campo com dados de subsuperfície. Finalmente, a divisão estratigráfica obtida neste trabalho foi incorporada a um amplo arcabouço desenvolvido para o Andar Dom João em diversas bacias do nordeste brasileiro e na África (Küchle et al. 2011).
CONTEXTO GEOLÓGICO A porção emersa da Bacia de Almada localiza-se no litoral Centro-Sul do estado da Bahia, entre os municípios de Itacaré a Norte e Ilhéus a Sul. Em terra, a bacia possui geometria romboédrica sendo limitada a Norte pelo Alto de Taipus e a Sul pelo Alto de Olivença (Fig. 1). Estes altos são controlados por zonas de falhas normais que colocam o embasamento em bloco alto e a seção sedimentar, no baixo (Netto \& Sanches 1991). A próxima bacia a norte é a de Camamu, e a Sul, de Jequitinhonha. A oeste, a seção sedimentar está em contato por não conformidade com o embasamento cristalino e à leste estende-se mar adentro até a crosta oceânica.

A Bacia de Almada pertence ao conjunto de bacias da margem continental brasileira. A evolução destas segue um padrão sistemático bem definido, compreendendo primeiramente uma sequência continental, passando por uma fase transicional comumente evaporítica e, finalmente, evoluindo para uma sequência marinha.

A evolução tectônica da Bacia de Almada está relacionada a duas fases de subsidência distintas:
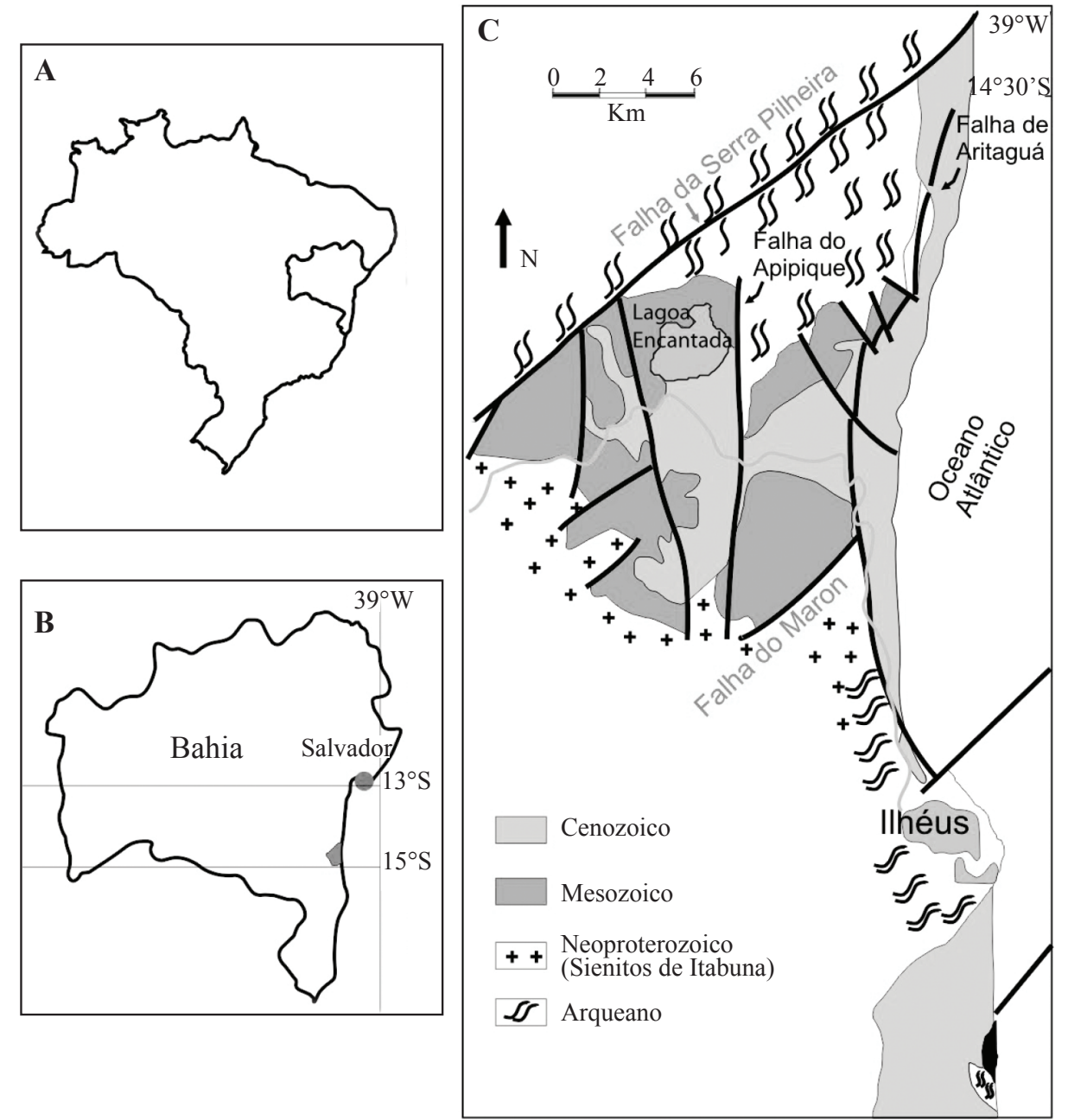

Figura 1 - Localização da área de estudo. (A) mapa do Brasil com o contorno do estado da Bahia; (B) estado da Bahia com a porção emersa da Bacia de Almada assinalada; (C) arcabouço estrutural simplificado demonstrando as falhas limitrofes da bacia com direção N50E (modificado de Netto \& Sanches 1991). 
rifte e termal. A primeira ocorre durante a fase de fraturamento do Gondwana (tafrogênese), relacionado à extensão litosférica (Chang \& Kowsmann 1987). Tal fase é responsável pela configuração do arcabouço estrutural principal destas bacias, com blocos tectônicos basculados, separados por falhas normais sintéticas e antitéticas e formando diversos sistemas de grábens e horsts (Ojeda 1983). Subsequentemente, ocorre a fase de subsidência termal, devido ao resfriamento da anomalia térmica produzida durante a extensão crustal (Chang \& Kowsmann 1987).
Falhas normais sintéticas e antitéticas de direção N-S aproximadamente dividem a Bacia de Almada em três compartimentos estruturais (Netto \& Sanches 1991): oeste, central e leste. O compartimento oeste estende-se por praticamente metade da área emersa da bacia, sendo limitado a leste pela falha do Apipique, apresentando uma espessura estimada da seção sedimentar de $200 \mathrm{~m}$. Entre as falhas do Apipique e de Aritaguá, está o compartimento central, no qual a seção sedimentar possui espessuras da ordem de $500 \mathrm{~m}$. A leste da falha de Aritaguá, situa-se o compartimento leste, no qual a espessura da seção sedimentar ultrapassa 2.000 m (Fig. 2).

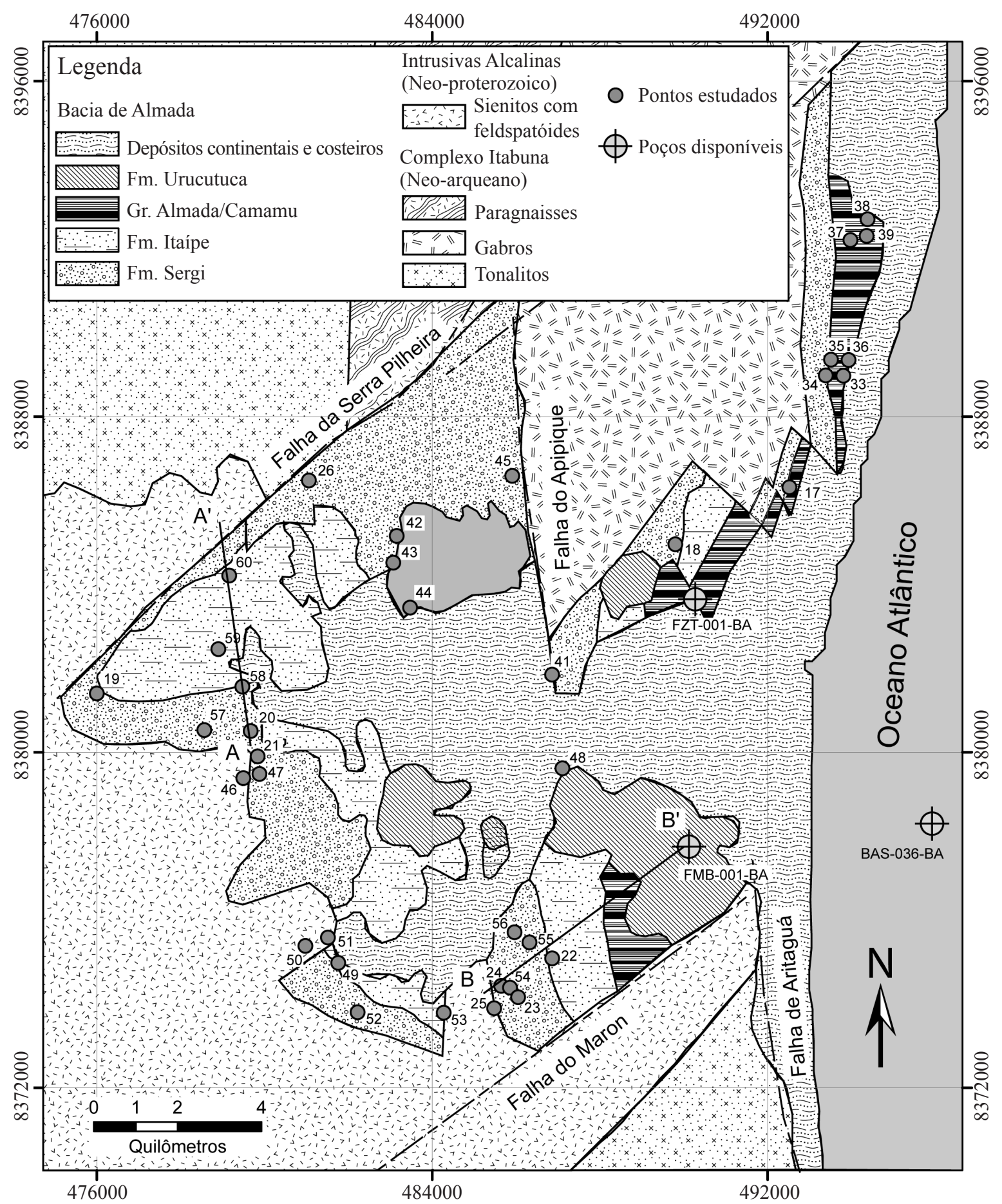

Figura 2 - Mapa geológico da Bacia de Almada (modificado de Carvalho 1965). 
A acumulação da Formação Sergi ocorreu durante o estágio pré-rifte das bacias marginais brasileiras, o qual representa uma longa subsidência e consequente geração de uma ampla bacia intracratônica. Esta formação compõe-se de um sistema deposicional continental, caracterizado por alternâncias entre arenitos fluviais e eólicos e pelitos lacustres oxidados (Pierini et al. 2010). Cerca de $90 \%$ da Formação Sergi é composta por arenitos e, em geral, os depósitos demonstram um padrão de granocrescência ascendente (Scherer et al. 2007). Essa formação ocorre nas Bacias de Almada, Camamu, Tucano, Jatobá e Recôncavo, sendo a primeira o registro mais a Sul da Formação Sergi.

\section{FÁCIES E ASSOCIAÇÕES DE FÁCIES}

Como resultados do trabalho de campo, 14 litofácies foram descritas e interpretadas, as quais estão listadas na Tab. 1 de acordo com a nomenclatura de Miall (1996). Posteriormente, as litofácies foram agrupadas em cinco associações de fácies distintas, que estão descritas e interpretadas a seguir.

Tabela 1 - Resumo das principais características das litofácies descritas em campo

\begin{tabular}{|c|c|c|c|}
\hline Fácies & Ocorrência & Descrição & Interpretação \\
\hline Gt & $\begin{array}{l}47,7 \mathrm{~m} \\
13 \mathrm{pts}\end{array}$ & $\begin{array}{l}\text { Conglomerados clastosuportados com moda em grânulos a blocos, seixos } \\
\text { e blocos arredondados a sub-arred., e grânulos e areia subangulosos a } \\
\text { angulosos. Organizados em sets de estratificação cruzada acanalada com } \\
\text { ou sem gradação normal de } 0,3 \text { até } 3 \mathrm{~m} \text { de espessura. Por vezes, ocorrem } \\
\text { como lags centimétricos na base de ciclos com gradação normal. }\end{array}$ & $\begin{array}{l}\text { Preenchimento de pequenos } \\
\text { canais }\end{array}$ \\
\hline Gh & $\begin{array}{l}8 \mathrm{~m} \\
7 \mathrm{pts}\end{array}$ & $\begin{array}{l}\text { Conglomerados clastosuportados com moda em grânulos a seixos, } \\
\text { pobremente selecionados, clastos subarredondados a subangulosos. } \\
\text { Organizados em sets de estratificação plano-paralela com ou sem } \\
\text { gradação normal, de } 0,3 \text { a } 1,5 \text { m de espessura. }\end{array}$ & $\begin{array}{l}\text { Formas de leito longitudinais, } \\
\text { depósitos residuais (lags) }\end{array}$ \\
\hline $\mathrm{Gm}$ & $\begin{array}{l}3,75 \mathrm{~m} \\
9 \mathrm{pts}\end{array}$ & $\begin{array}{l}\text { Conglomerados clastosuportados, maciço, com moda em grânulos a seixos, } \\
\text { clastos subarredondados a arredondados, moderadamente selecionados. } \\
\text { Dispostos em camadas tabulares ou lenticulares com } 10 \text { a } 50 \mathrm{~cm} \text { de } \\
\text { espessura, na maioria das vezes na base dos ciclos de gradação normal. }\end{array}$ & Fluxo de detritos \\
\hline St & $\begin{array}{l}73 \mathrm{~m} \\
15 \mathrm{pts}\end{array}$ & $\begin{array}{l}\text { Arenitos finos a conglomeráticos, bem a moderadamente selecionados, } \\
\text { dispostos em sets de estratificação cruzada acanalada com } 0,1 \text { até } 1 \mathrm{~m} \text { de } \\
\text { espessura, com gradação normal. }\end{array}$ & $\begin{array}{l}\text { Dunas } 3 \mathrm{D} \text {, cristas sinuosas ou } \\
\text { linguoides }\end{array}$ \\
\hline $\mathrm{Sl}$ & $\begin{array}{l}13,8 \mathrm{~m} \\
7 \mathrm{pts}\end{array}$ & $\begin{array}{l}\text { Arenitos finos a conglomeráticos, bem a moderadamente selecionados, } \\
\text { dispostos em sets tabulares de estratificação cruzada de baixo ângulo com } \\
\text { ou sem gradação normal, de } 0,5 \text { até } 3,5 \mathrm{~m} \text { de espessura. }\end{array}$ & $\begin{array}{l}\text { Preenchimentos de suaves } \\
\text { depressões (scour fills), dunas } \\
\text { atenuadas, antidunas }\end{array}$ \\
\hline Sh & $\begin{array}{l}12,5 \mathrm{~m} \\
5 \mathrm{pts}\end{array}$ & $\begin{array}{l}\text { Arenitos finos a conglomeráticos, bem selecionados, dispostos em sets de } \\
\text { estratificação plano-paralela de } 0,3 \text { a } 2 \text { m de espessura, com gradação normal. }\end{array}$ & $\begin{array}{l}\text { Formas de leito plano (regime } \\
\text { de fluxos superior ou crítico) }\end{array}$ \\
\hline $\mathrm{Sm}$ & $\begin{array}{l}25 \mathrm{~m} \\
4 \mathrm{pts}\end{array}$ & $\begin{array}{l}\text { Arenitos finos a grossos, bem selecionados, dispostos em camadas com } \\
\text { gradação normal ou sem organização interna, de } 1,5 \text { até } 3,5 \text { m de espessura. }\end{array}$ & $\begin{array}{l}\text { Depósitos de fluxos } \\
\text { hiperconcentrados, fluidizações } \\
\text { ou intensa bioturbação }\end{array}$ \\
\hline $\mathrm{Sr}$ & $\begin{array}{l}20 \mathrm{~cm} \\
1 \mathrm{pt}\end{array}$ & $\begin{array}{l}\text { Arenito muito fino com ripples de corrente, disposto em camada tabular } \\
\text { de } 20 \mathrm{~cm} \text { de espessura com gradação normal. }\end{array}$ & $\begin{array}{l}\text { Marcas onduladas (regime de } \\
\text { fluxo inferior) }\end{array}$ \\
\hline $\mathrm{Fl}$ & $\begin{array}{l}7,3 \mathrm{~m} \\
4 \mathrm{pts}\end{array}$ & $\begin{array}{l}\text { Pelitos de coloração marrom e cinza escuro, com laminação plano-paralela, } \\
\text { dispostos em camadas tabulares de menos de } 10 \mathrm{~cm} \text { até } 1,5 \mathrm{~m} \text { de espessura. }\end{array}$ & $\begin{array}{l}\text { Decantação de partículas em } \\
\text { suspensão }\end{array}$ \\
\hline $\mathrm{Fr}$ & $\begin{array}{l}2,3 \mathrm{~m} \\
1 \mathrm{pt}\end{array}$ & $\begin{array}{l}\text { Siltitos marrons com marcas onduladas de pequeno porte, dispostos em } \\
\text { camadas tabulares de } 0,4 \text { a } 1,5 \mathrm{~m} \text { de espessura. }\end{array}$ & $\begin{array}{l}\text { Marcas onduladas (regime de } \\
\text { fluxo inferior) }\end{array}$ \\
\hline Flc & $\begin{array}{l}3 \mathrm{~m} \\
1 \mathrm{pt}\end{array}$ & $\begin{array}{l}\text { Folhelhos cinzentos com laminação plano-paralela, ricos em matéria } \\
\text { orgânica, com restos vegetais dispostos em camadas tabulares com } 5 \text { a } 30 \mathrm{~cm} \\
\text { de espessura. }\end{array}$ & $\begin{array}{l}\text { Decantação de partículas em } \\
\text { suspensão ricas em matéria } \\
\text { orgânica }\end{array}$ \\
\hline St(eólico) & $\begin{array}{l}72 \mathrm{~m} \\
3 \mathrm{pts}\end{array}$ & $\begin{array}{l}\text { Arenitos finos a médios bem a muito bem selecionado, grãos arredondados } \\
\text { e com esfericidade alta, dispostos em sets de estratificação cruzada } \\
\text { acanalada de grande porte, com } 1 \text { a } 4 \text { m de espessura, compostos por } \\
\text { depósitos de fluxo de grão e por laminações de marcas onduladas eólicas. }\end{array}$ & Dunas eólicas \\
\hline Sl(eólico) & $\begin{array}{l}5 \mathrm{~m} \\
1 \mathrm{pt}\end{array}$ & $\begin{array}{l}\text { Arenitos finos, muito bem selecionados, disposto em sets de estratificação } \\
\text { cruzada de baixo ângulo com espessuras de } 40 \mathrm{~cm} \text { até } 4,5 \mathrm{~m} \text {. Os estratos } \\
\text { cruzados são compostos por laminações de marcas onduladas eólicas. }\end{array}$ & $\begin{array}{l}\text { Lençóis de areia } \\
\text { eólicos }\end{array}$ \\
\hline Sh(eólico) & $\begin{array}{l}2 \mathrm{~m} \\
1 \mathrm{pt}\end{array}$ & $\begin{array}{l}\text { Arenitos finos muito bem selecionados, dispostos em camadas tabulares } \\
\text { de estratificação plano-paralela de } 30 \text { a } 50 \mathrm{~cm} \text { de espessura. }\end{array}$ & Depósitos de interdunas \\
\hline
\end{tabular}




\section{Associação de fácies de cinturão de canais fluviais entrelaçados}

DESCRIÇÃO A associação de fácies do cinturão de canais fluviais entrelaçados (AFCFE) é composta por corpos arenosos com geometria em lençol, formando complexos amalgamados multilaterais e multiepisódicos (Fig. 3), tendo espessuras variando entre 1 e $8 \mathrm{~m}$ (Fig. 4). São limitados na base por superfícies erosivas planas ou côncavas sem incisões significativas. Lags centimétricos de conglomerados maciços ou estratificados são comuns ao longo destas superfícies.

Internamente, tais corpos são caracterizados por sucessões granodecrescentes de 0,3 a $1 \mathrm{~m}$, compostas pelas litofácies Gm, Gt, Gh e St organizadas em sets com gradação normal. No topo de alguns destes ciclos, ocorrem arenitos maciços, com laminação plano-paralela ou de baixo ângulo (litofácies $\mathrm{Sm}$, $\mathrm{Sh}$ and $\mathrm{Sl}$ ).

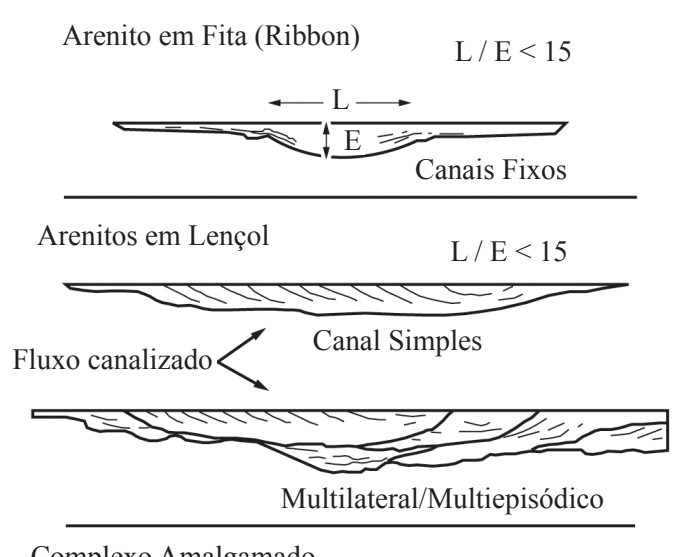

Complexo Amalgamado

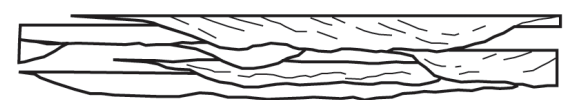

Figura 3 - Classificação geométrica dos corpos arenosos de canais fluviais baseada na razão largural profundidade (L/E), associada ao preenchimento interno (modificado de Hirst 1991).
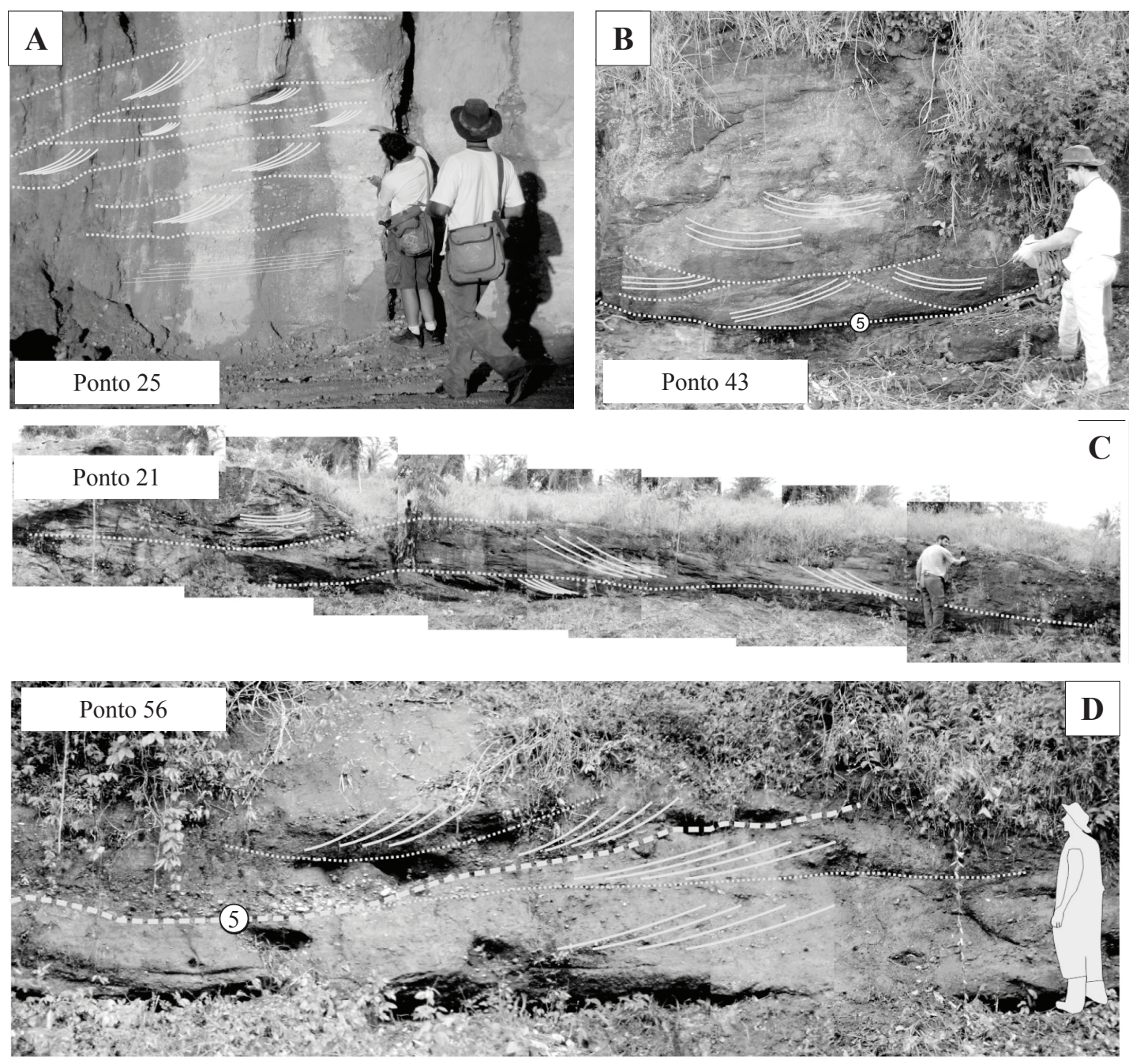

Figura 4 - Geometria dos corpos arenosos das associações de fácies de canais fluviais efêmeros. (A) vista paralela ao paleofluxo mostrando as estratificações cruzadas limitadas por superficies planas a inclinadas; (B) superficie da base de canal e sets de estratos cruzados em vista transversal ao paleofluxo; (C) sets de estratificação cruzada limitados por superficies planas (vista paralela ao paleofluxo); (D) linha tracejada marcando uma superficie de base de canal (5 $5^{a}$ ordem) em vista oblíqua ao paleofluxo. 
Em apenas um afloramento foi observado um conglomerado com intraclastos argilosos. A Fig. 5 apresenta estas litofácies em detalhes.

A análise das paleocorrentes na AFCFE indica fluxo preferencial dos canais fluviais para o quadrante NE.

\section{INTERPRETAÇÃO Os corpos arenosos descri-} tos podem ser interpretados como depósitos de canais fluviais. Geometria em lençol, predominância de sedimentos grossos e pequena dispersão da paleocorrente sugerem que essa associação de fácies represente o preenchimento de um cinturão de canais fluviais entrelaçados (Scherer et al. 2007). Os arenitos com laminação plano-paralela (Sh) a baixo ângulo ( $\mathrm{Sl}$ ) representam períodos de inundações episódicas de alta energia, marcando uma passagem para regime de fluxo superior. Estas fácies formam-se preferencialmente
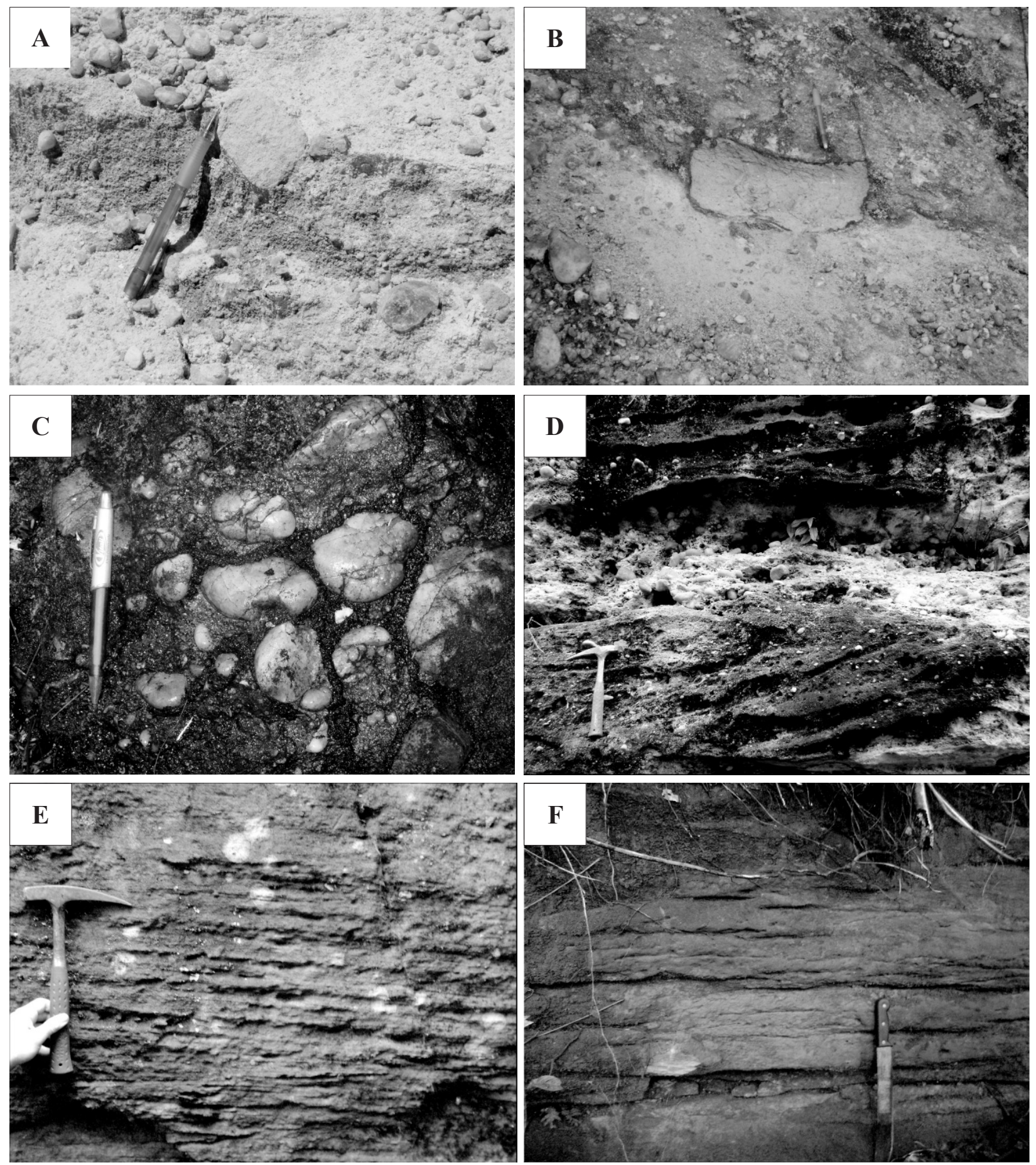

Figura 5 - Detalhe das principais fácies das associações de fácies de canais fluviais efêmeros. (A) seixo de arenito; (B) intraclasto argiloso em conglomerado com estratificação cruzada acanalada (Gt); (C) conglomerado com clastos tamanho bloco (Gt); (D) sets de arenitos conglomeráticos com estratificação cruzada acanalada (St); (E) fácies Sl (notar truncamento em baixo ângulo dos estratos) e (F) fácies Sh, com seixos dispersos. 
em condições de baixas profundidades de lâmina da água ( $<0,5 \mathrm{~m}$ ) (Miall 2006), sendo interpretadas, portanto, como a fase final do preenchimento dos canais.

Os sets de estratificação cruzada representam depósitos das formas de leito arenosas ou cascalhosas de crista sinuosa (dunas 3D subaquosas), que preencheram os canais fluviais (Miall 2006). A ausência de fácies pelíticas entre os corpos arenosos indica alta mobilidade lateral dos canais entrelaçados (Spalletti \& Piñol 2005) e pobre desenvolvimento de planícies de inundação nas margens do cinturão dos canais. Os conglomerados com intraclastos argilosos indicam erosão dos poucos depósitos da planície de inundação, depositados nas porções laterais dos canais. As superfícies erosivas, que definem a base dos corpos arenosos e são capeadas por conglomerados intraformacionais, podem ser interpretadas como superfícies de quinta ordem (Miall 1996).

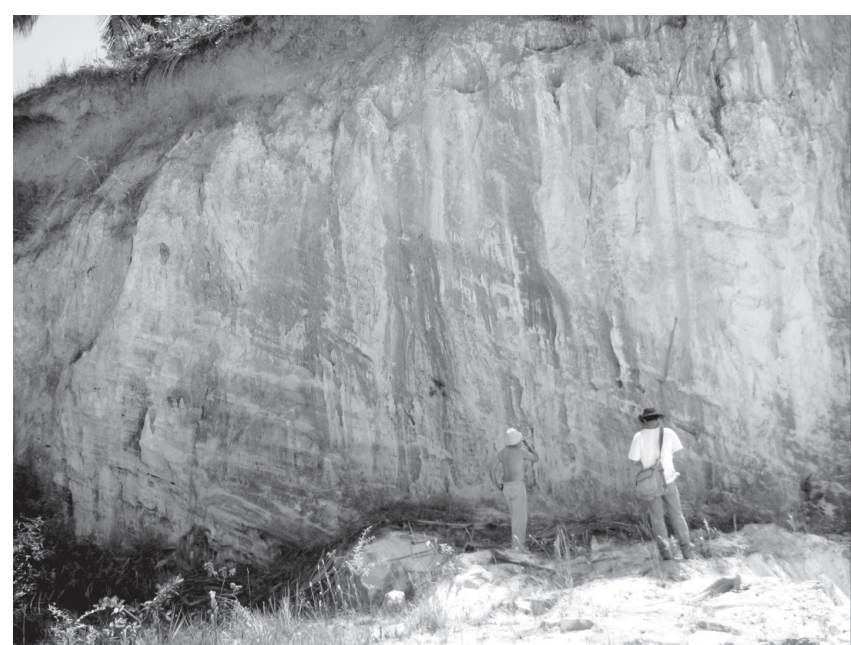

\section{Associação de fácies de dunas eólicas}

DESCRIÇÃO A associação das fácies de dunas eólicas (AFDE) é composta por arenitos finos a médios, bem selecionados, com grãos arredondados e de alta esfericidade. São dispostos em sets de estratificação cruzada acanalada com espessura de $1 \mathrm{a} 4 \mathrm{~m}$, separados por superfícies sub-horizontais (Fig. 6). Os estratos cruzados são constituídos, nas porções mais íngremes dos foresets, por lâminas com gradação inversa interna, geradas por processos de fluxo de grãos. Na base dos sets, os estratos tangenciam a superfície basal, sendo constituídos por laminações de marcas onduladas eólicas (litofácies St(e)), como observado na Fig. 7.

As paleocorrentes medidas nos estratos cruzados indicam a migração das dunas eólicas para o quadrante SW dominantemente.

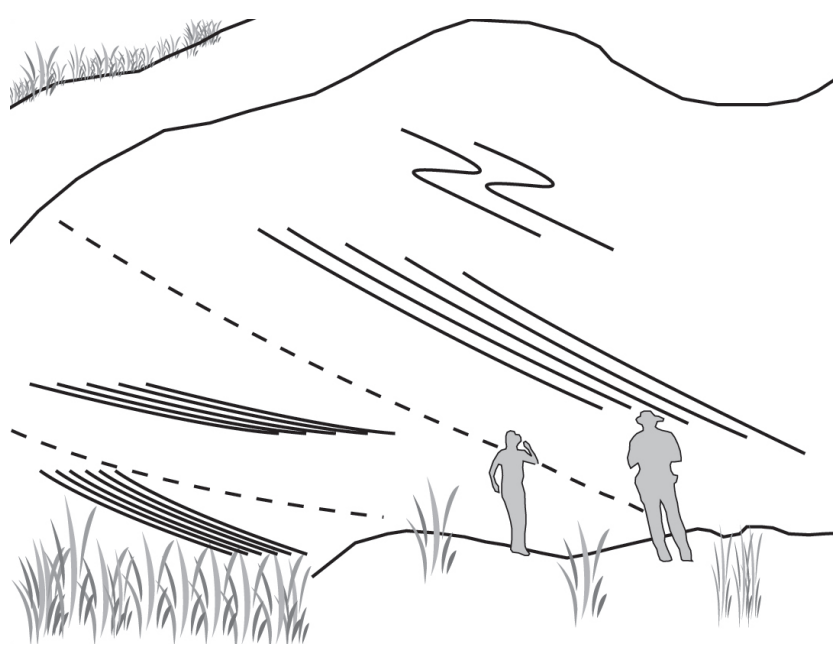

Figura 6 - Sets de estratificação cruzada de grande porte e feições de deslizamento no topo do afloramento.

A

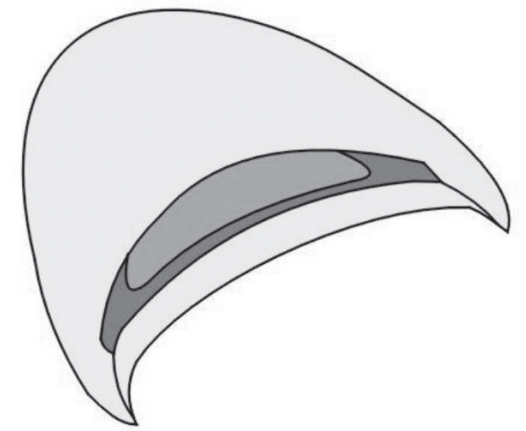

Depósitos de marcas onduladas eólicas Depósitos de queda livre de grãos Depósitos de fluxo de grãos

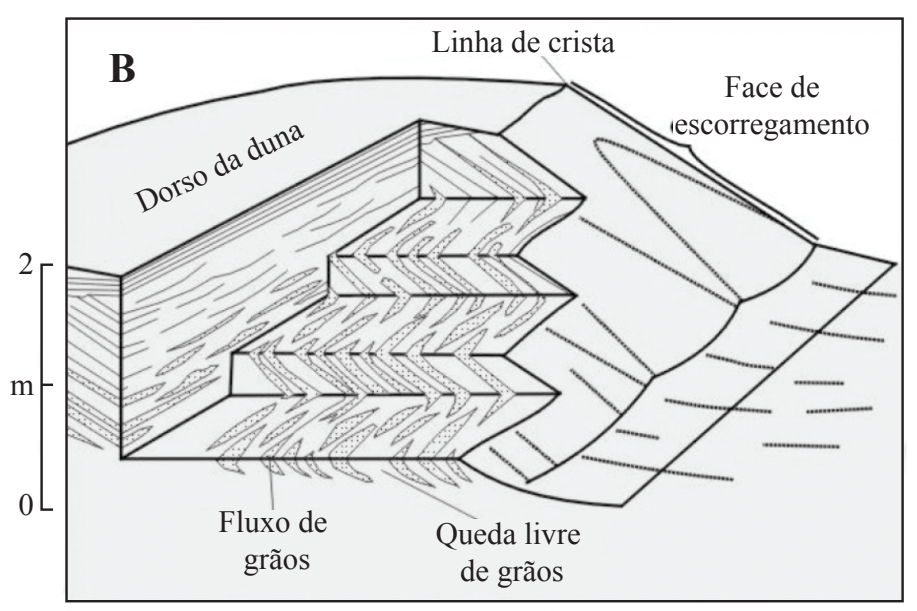

Figura 7-(A) Distribuição dos depósitos em uma duna eólica; (B) seções horizontais e transversais mostrando as estratificações eólicas internas à duna (modificado de Hunter 1977). 
INTERPRETAÇÃO A boa seleção, o arredondamento e a esfericidade dos grãos, juntamente com as estratificações cruzadas de grande porte compostas por depósitos de fluxo de grãos e marcas onduladas eólicas, permitem interpretar essa associação de fácies como depósitos residuais de dunas eólicas (Hunter 1977). A geometria acanalada dos estratos cruzados,

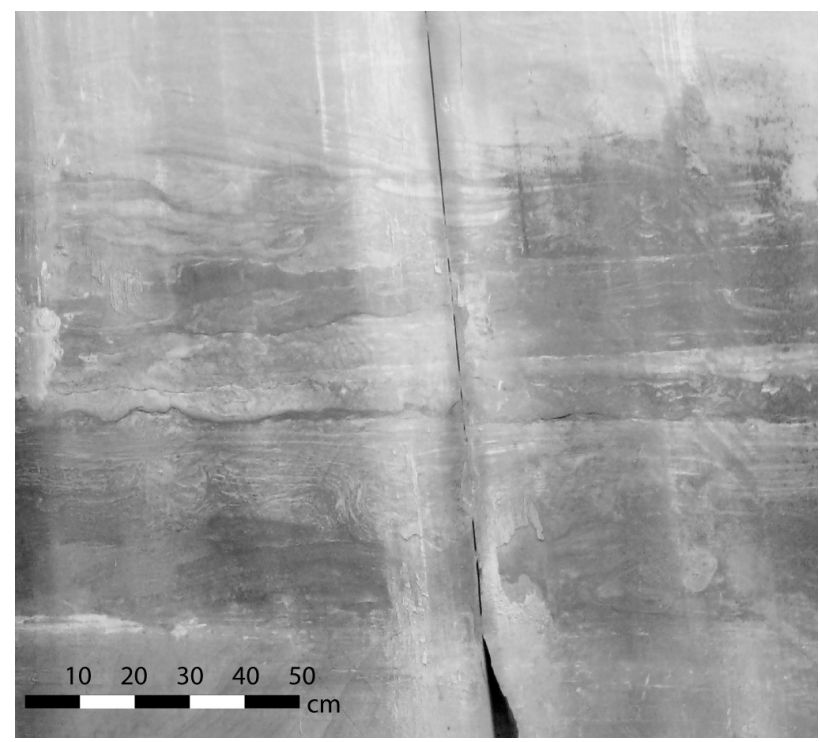

Figura 8 - Depósito de interduna com dobras convolutas formadas por processos de escape de fluidos. associada com o sentido unimodal do mergulho dos foresets, indicam dunas eólicas crescentes, com crista curva (dunas 3D). As superfícies sub-horizontais que limitam os sets de estratificações cruzadas podem ser interpretadas como de primeira ordem, geradas pelo cavalgamento de dunas eólicas (Mountney 2006).

\section{Associação de fácies de interdunas eólicas}

DESCRIÇÃO A associação de fácies de interdunas eólicas (AFIE) inclui arenitos finos, bem selecionados, possuindo grãos arredondados e com alta esfericidade. Estes arenitos são organizados em pacotes com 0,3 a $4 \mathrm{~m}$ de espessura, intercalados aos sets de estratificação cruzada. Tais pacotes são caracterizados por laminações plano-paralelas e cruzadas de baixo ângulo compostas essencialmente por laminações de marcas onduladas eólicas (litofácies $\mathrm{Sh}(\mathrm{e})$ e $\mathrm{Sl}(\mathrm{e})$ ). Localmente, observam-se dobras convolutas (Fig. 8).

INTERPRETAÇÃO Os arenitos com estratificações plano-paralelas e cruzadas de baixo ângulo, compostas por laminações de marcas onduladas eólicas e intercalados aos sets de dunas eólicas são interpretados como depósitos de interdunas eólicas

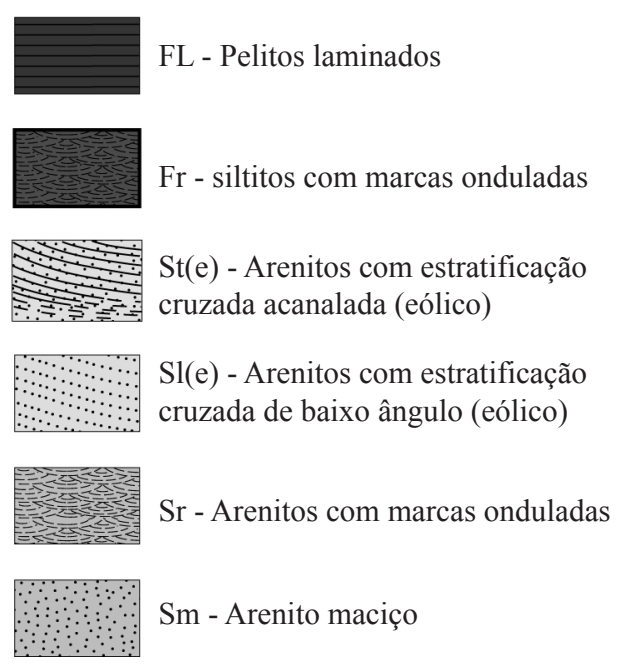

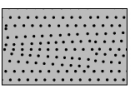

S1 - Arenito com estratificação cruzada de baixo ângulo

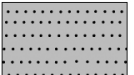

Sh - Arenito com estratificação plano-paralela

St - Arenito com estratificação cruzada acanalada

Gt - Conglomerado a grânulos com estratificação cruzada acanalada

Gt - Conglomerado a seixos com estratificação cruzada acanalada

Gh - Conglomerado com estratificação plano-paralela

Gm - Conglomerado a blocos maciço

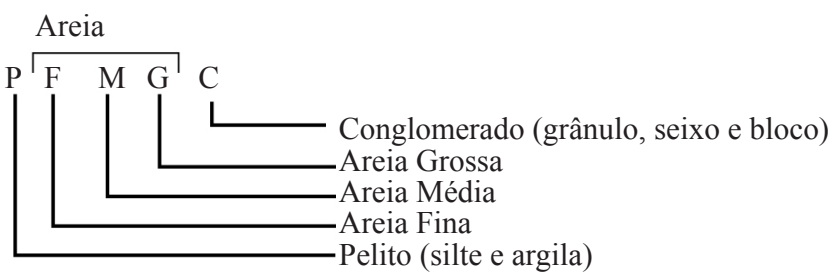

Figura 9 - Legenda de litofácies e escala granulométrica. 
(Mountney 2006, Dias \& Scherer 2008). As dobras convolutas observada são formadas por processos de fluidização, originados pelo peso da duna eólica sobrejacente (Mountney \& Thompson 2002, Dias \& Scherer 2008), como observado na Fig. 9.

\section{Associação de fácies de lençóis de areia eólicos}

DESCRIÇÃO A associação de fácies de lençóis de areia eólicos (AFLE) foi encontrada em apenas um afloramento (Fig. 10A). É formada por um pacote de aproximadamente $3 \mathrm{~m}$ de espessura, composto por arenitos médios a grossos, quartzosos, bem selecionados e com laminações cruzadas de baixo ângulo ( $\mathrm{Sl}(\mathrm{e})$ ), compostos por laminações transladantes cavalgantes, inversamente gradadas, com espessuras de 2 a $8 \mathrm{~mm}$.
INTERPRETAÇÃO Os arenitos com laminações cruzadas de baixo ângulo e gradações inversas internas aos estratos podem ser interpretados como lençóis de areia eólicos formados pela migração e cavalgamento de marcas onduladas eólicas subcríticas sobre uma superfície deposicional seca (Hunter 1977).

\section{Associação de fácies lacustre}

DESCRIÇÃO A associação de fácies lacustre (AFL) é composta dominantemente por pelitos laminados (Fl), com colorações amarronzadas, acinzentadas e avermelhadas, dispostos em pacotes tabulares de até $3 \mathrm{~m}$ (Fig. 10). Localmente, podem ser observadas camadas tabulares, decimétricas, de arenitos finos a médios maciços ( $\mathrm{Sm}$ ) ou com estratificação cruzada
A

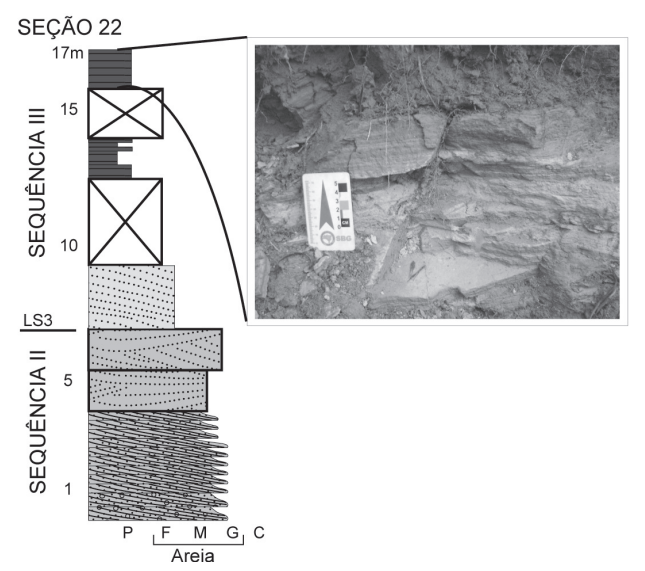

\section{B}

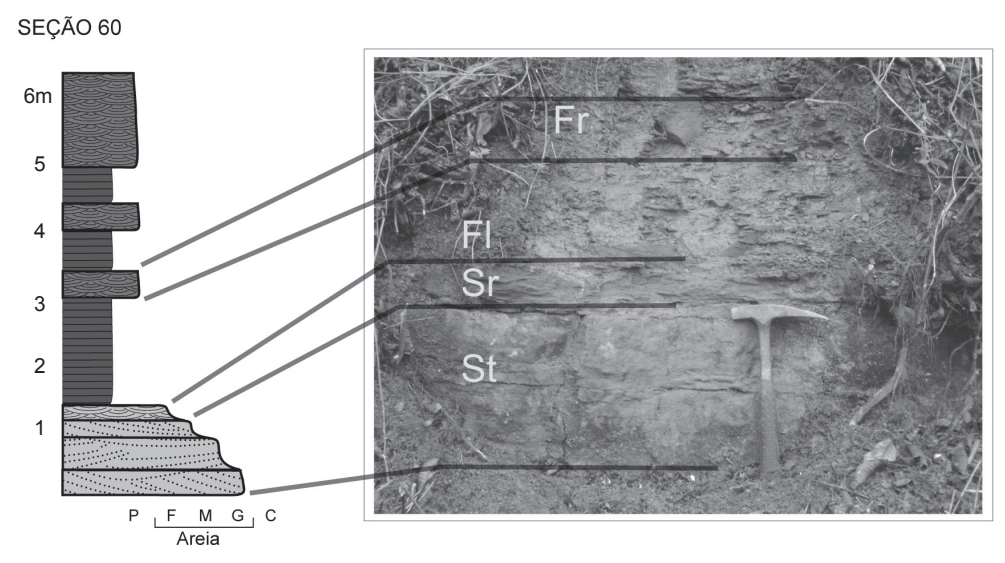

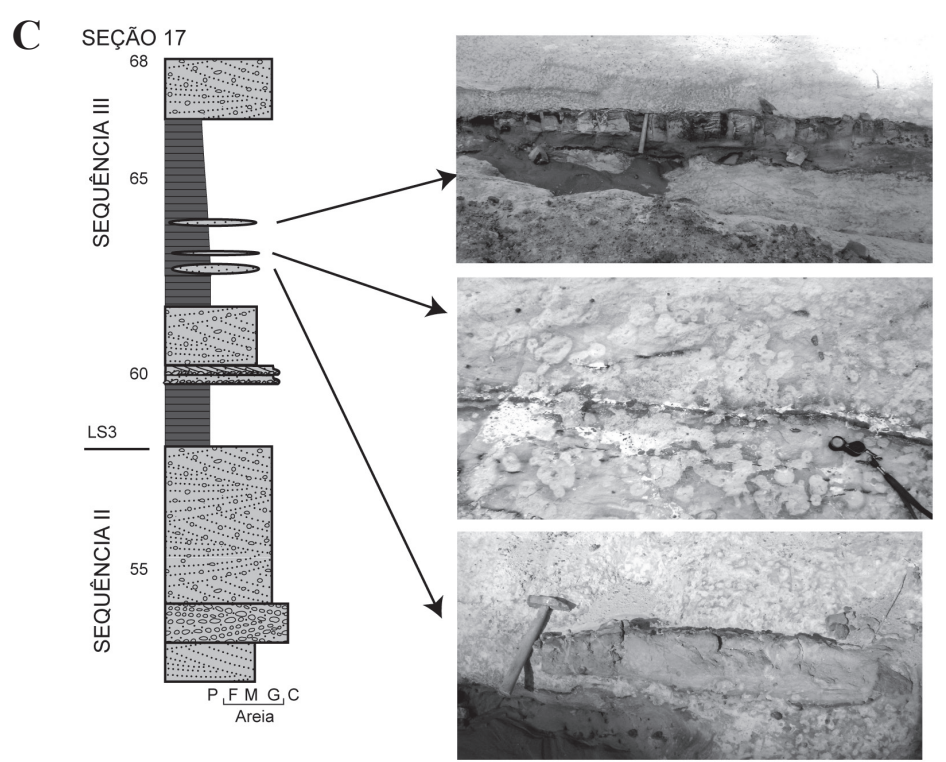

Figura 10 - Perfis colunares ilustrando a Associação de Fácies Lacustre. (A) Porção sul da bacia, na qual lençóis de areia eólicos (litofácies Sl(e)) sobrepõem as associações de fácies de canais fluviais efêmeros da sequência II, sendo por sua vez sobrepostos por pelitos laminados da associação de fácies lacustre (litofácies Fl). (B) Nas áreas a Norte da bacia, os pelitos laminados com siltitos com laminação de marcas onduladas (litofácies Fr) recobrem diretamente os depósitos fluviais da sequência II. (C) Espesso pacote de pelitos laminados (litofácies Fl) intercalados com camadas lenticulares e tabulares de arenitos finos maciços e com estratificações cruzadas. 
acanalada ( $\mathrm{St}$ ) e arenitos finos e siltitos com laminação cruzada de marcas onduladas (Sr e Fr) (Fig. 10). $\mathrm{O}$ sentido de mergulho dos estratos cruzados indica paleocorrente para NW. Por vezes, são encontrados icnofósseis tubulares horizontais e verticais com diâmetros milimétricos (Fig. 11).

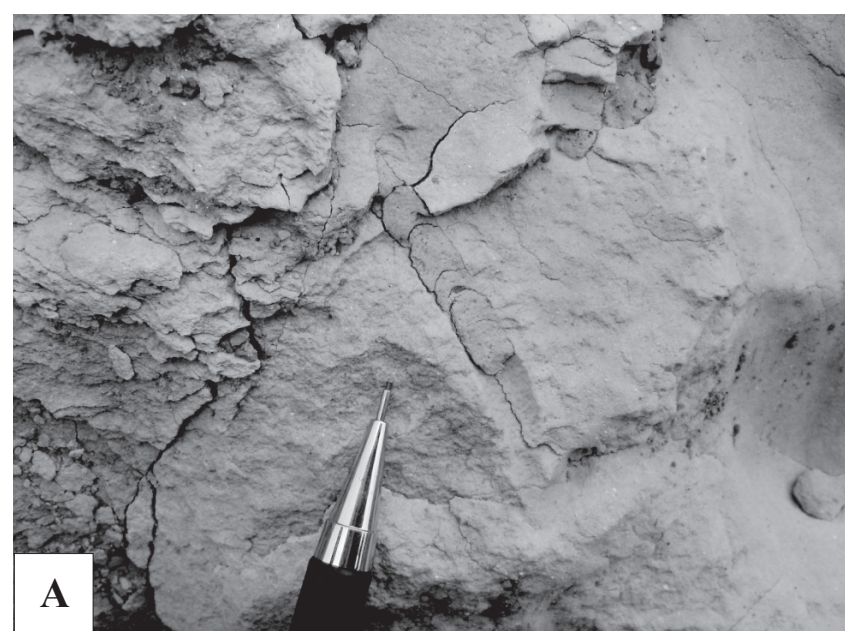

INTERPRETAÇÃO Os pelitos laminados são interpretados como o assentamento de partículas por decantação em um corpo de água estável. A coloração avermelhada a amarronzada indica mudanças nas condições oxirredutoras do ambiente, possivelmente causadas por oscilações no nível do lago (Miall 2006).

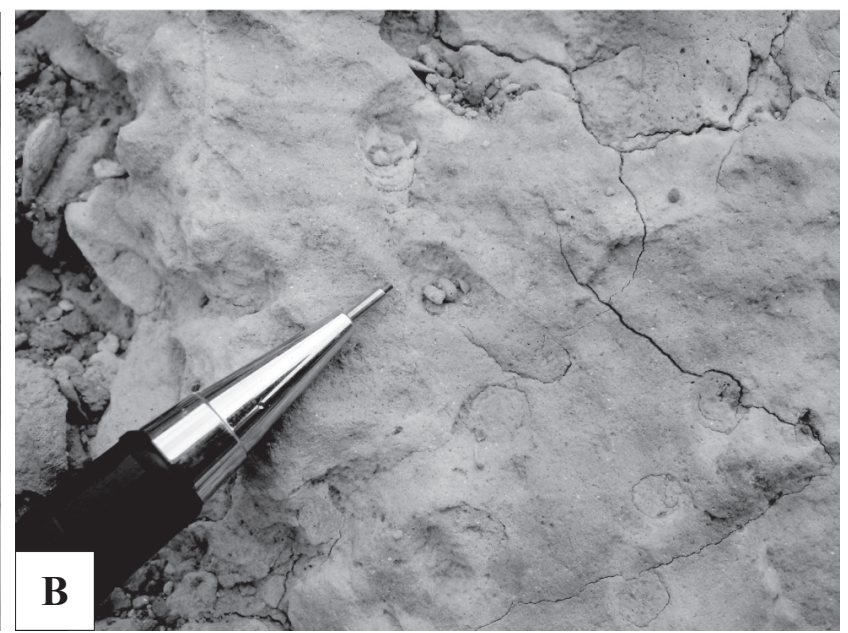

Figura 11 - Icnofósseis tubulares com diâmetros milimétricos encontrados internamente aos pelitos lacustres. Notar as diversas direções dos rastros.

$\mathrm{S}$

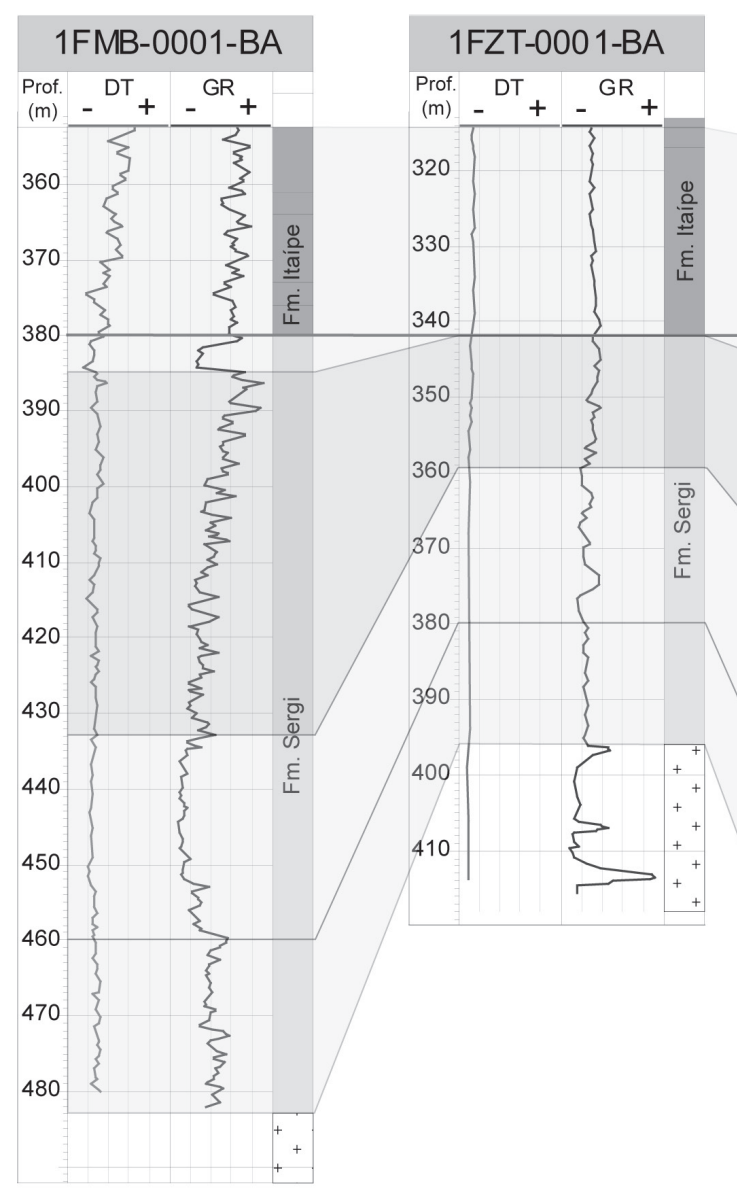

SE

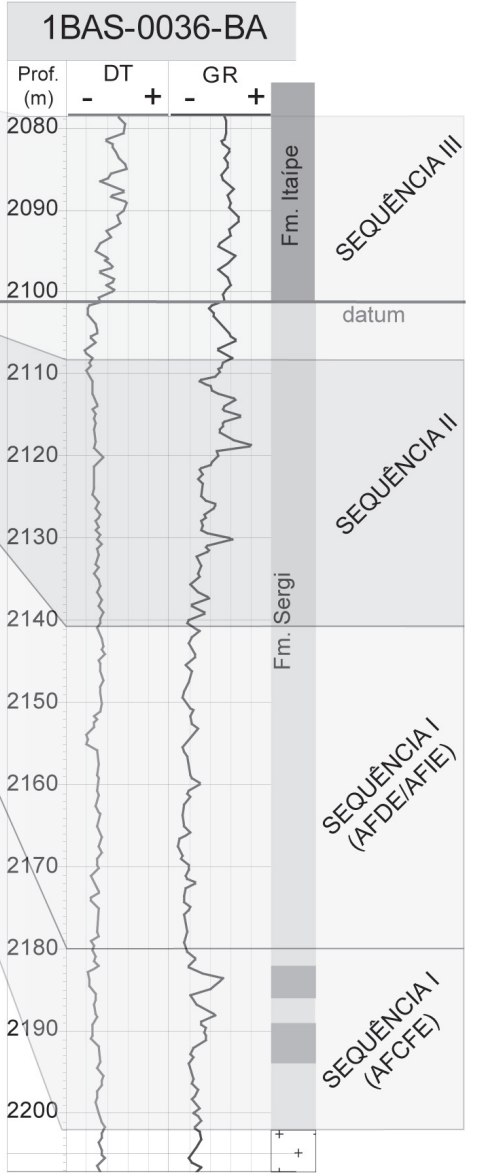

Figura 12 - Demarcação das sequências deposicionais nos três poços analisados, sendo utilizadas as curvas GR (raios gama) e DT (sônico). A localização dos poços encontra-se na Fig. 2. O datum utilizado é a base da Formação Itaípe (representando uma superfície de inundação regional). 
As camadas tabulares de arenitos e com estratificações cruzadas e siltitos com laminação cruzada de marcas onduladas são interpretadas como porções distais de frentes deltaicas construídas por rios.

ARCABOUÇO ESTRATIGRÁFICO O arcabouço estratigráfico proposto neste estudo é baseado nos trabalhos de Scherer et al. (2007) e Küchle et al. (2011). Scherer et al. (2007) propuseram um arcabouço estratigráfico com base nos conceitos da estratigrafia de sequências para a Formação Sergi na Bacia do Recôncavo. Posteriormente, Küchle et al. (2011) realizaram uma correlação regional por meio de diversas bacias do nordeste brasileiro (Almada, Camamu, Recôncavo, Araripe, Sergipe-Alagoas, Tucano e Jatobá) e África (Bacia de Gabão) para o Andar Dom João. Assim sendo, propõe-se que os depósitos flúvio-eólicos da Formação Sergi na Bacia de Almada sejam subdivididos em três sequências deposicionais limitadas por discordâncias regionais (Fig. 12).

Litoestratigraficamente, as sequências I e II correspondem à Formação Sergi, enquanto a III abrange o topo das Formações Sergi e Itaípe. Utilizando-se perfis geológicos, foi possível unir as informações dos poços com aquelas das seções colunares levantadas em campo (Fig. 13). Em posse desta correlação, elaborou-se

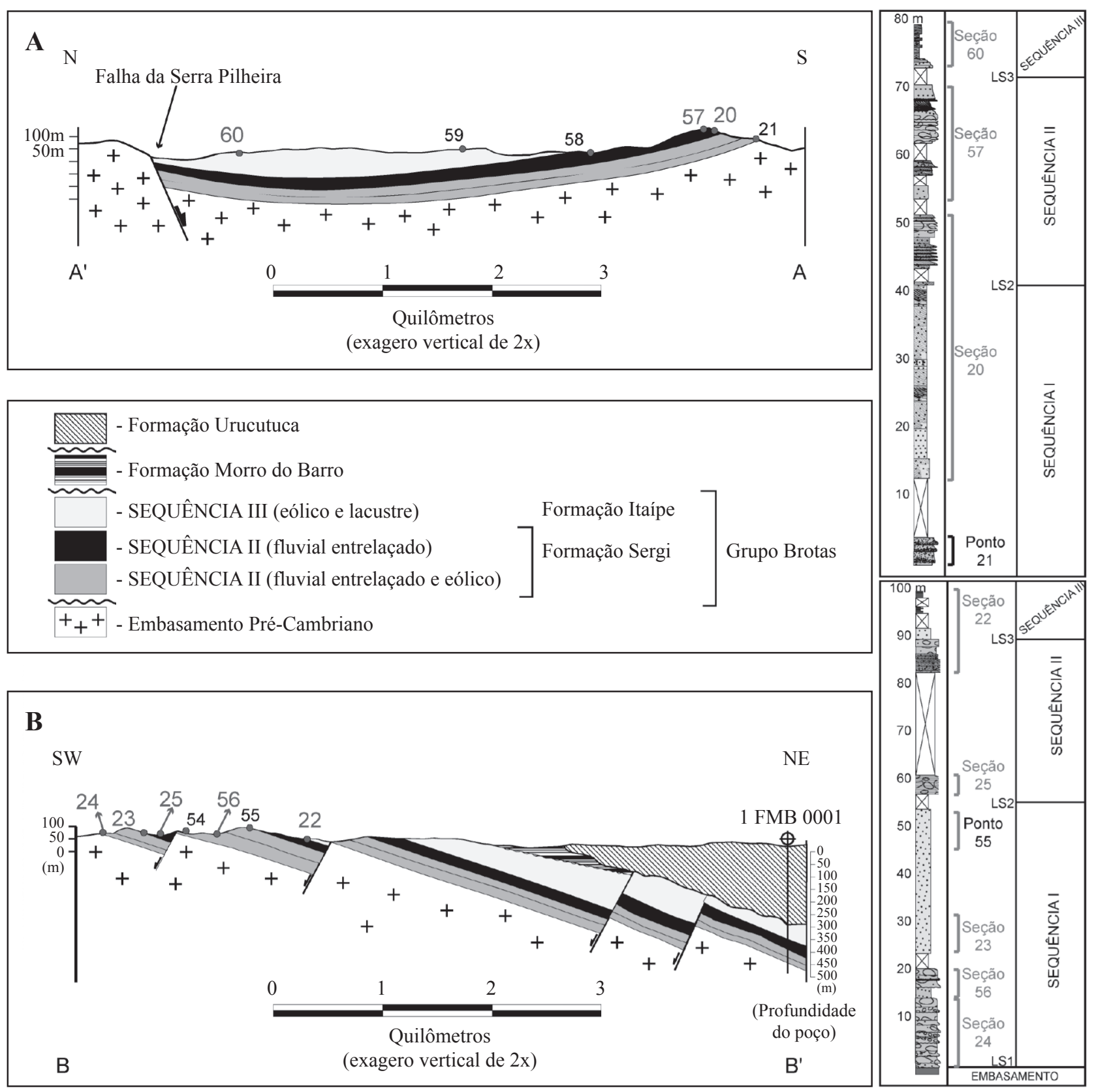

Figura 13 - (A) Perfil geológico A - A'e seção composta da região NW da Bacia de Almada; (B) perfil geológico $B-B$ ' correlacionado ao poço 1-FMB-0001 e seção composta para a região $S$ da bacia. A localização dos perfis encontra-se na Fig. 2. 
a seção composta para o intervalo estudado na Bacia de Almada (Fig. 14). Nela estão resumidas as principais características estratigráficas de cada sequência. Nos parágrafos seguintes, estes aspectos são abordados em detalhes.

Sequência I Foi identificada nos três poços analisados, em três seções colunares levantadas em campo e em outros afloramentos estudados. Tal sequência apresenta espessura entre 40 e $70 \mathrm{~m}$, sendo composta por associações de fácies de canais fluviais efêmeros (AFCFE), de dunas (AFDE) e interdunas (AFIE) eólicas. Nos perfis de raios gama dos três poços utilizados, as associações de fácies fluviais e eólicas apresentaram assinaturas distintas. Os depósitos fluviais possuem um padrão serrilhado, com valores

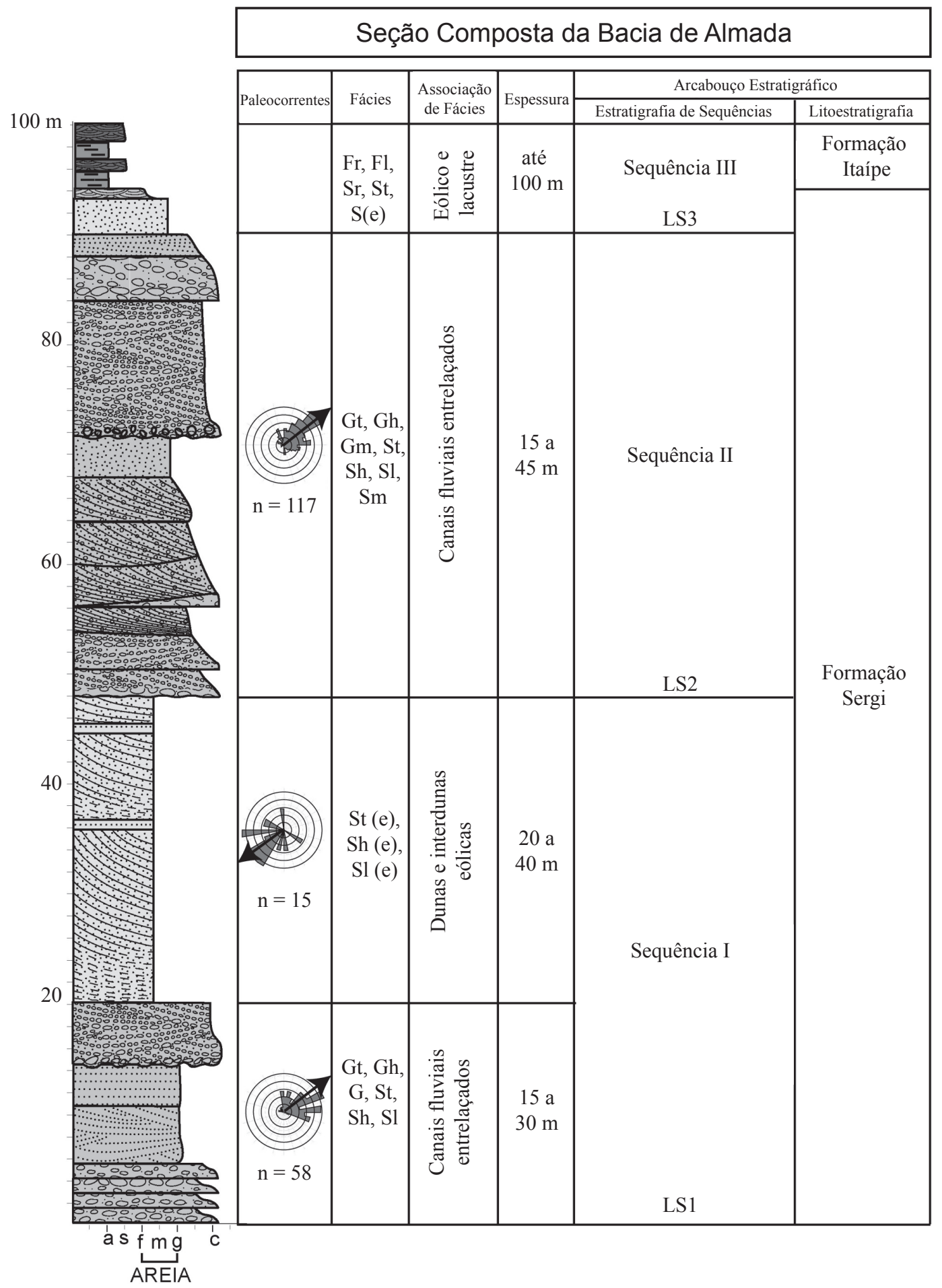

Figura 14 - Seção composta da Bacia de Almada com o resumo das principais características estratigráficas de cada sequência. 

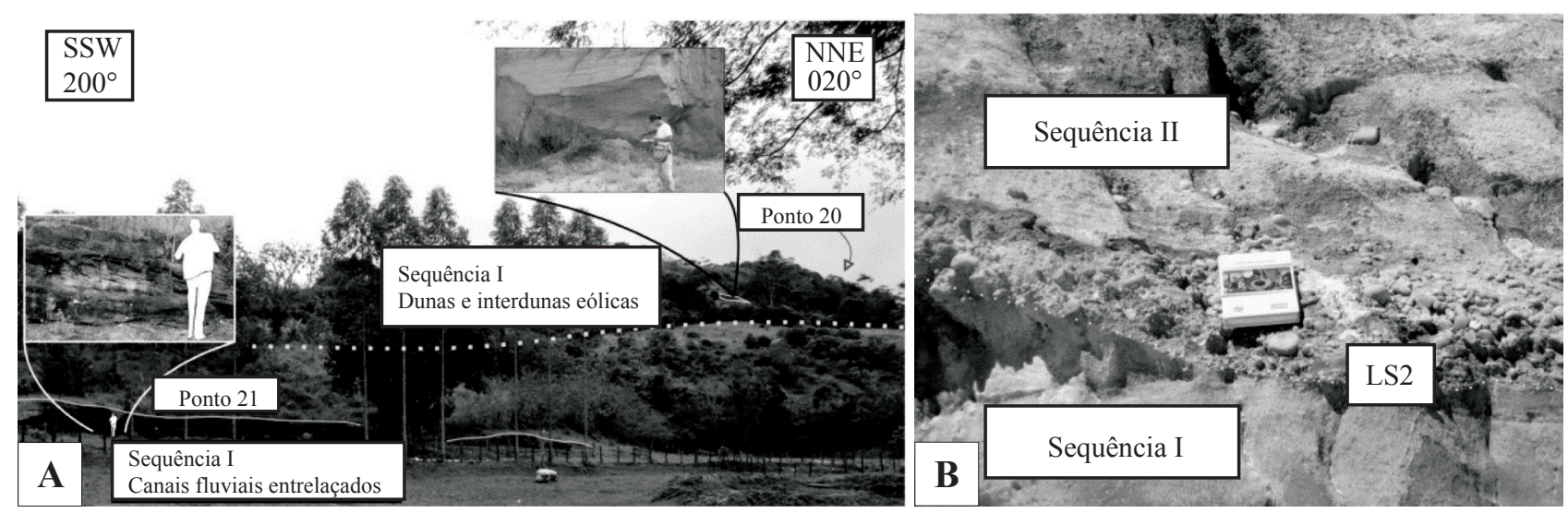

Figura 15 - (A) Passagem das associações de fácies de canais fluviais efêmeros para aquelas de dunas e interdunas eólicas na sequência I (linha pontilhada); (B) discordância entre as sequências I e II.

moderados de raios gama, contrastando os depósitos eólicos que apresentam padrão em 'caixote' com valores mais baixos de raios gama (Fig. 12).

O limite basal desta sequência (LS1) representa uma não conformidade com o embasamento cristalino, conforme verificado na localidade de Itariri e ilustrado no perfil B - B' (Fig. 13). A superfície limítrofe de topo (LS2) foi observada em afloramentos e poços. Trata-se de uma desconformidade com ampla extensão lateral, sobreposta por lags conglomeráticos com até $30 \mathrm{~cm}$ de espessura (Fig. 15B).

$\mathrm{O}$ contato entre a AFCFE e as AFDE/AFIE não foi localizado em nenhum dos afloramentos estudados, sendo inferido em uma única localidade da bacia (Fig. 15A). No entanto, esta passagem é facilmente identificada nos três poços estudados devido à mudança no padrão dos raios gama (Fig. 12).

As seções colunares e os mapas de paleocorrentes para a sequência I estão ilustrados nas Figs. 16 e 17, respectivamente. A AFDE possui paleocorrentes para SW, enquanto os depósitos da AFCFE apresentam paleocorrentes para NE.

Sequência II Apresenta espessura entre 15 e 45 m, tendo sido identificada em afloramentos e nos poços analisados. Apresenta padrão "serrilhado" do perfil de raios gama, com valores mais altos em comparação aos depósitos eólicos (Fig. 12).

O limite basal é uma desconformidade com a sequência II (LS2), e o topo é limitado por discordância com a sequência III, que é encontrada em afloramento e verificada nos poços (LS3). Tal superfície marca a interrupção do sistema aluvial desenvolvido neste período na Bacia de Almada (Fig. 15B).

A sequência II é constituída exclusivamente pela AFCFE, com características faciológicas

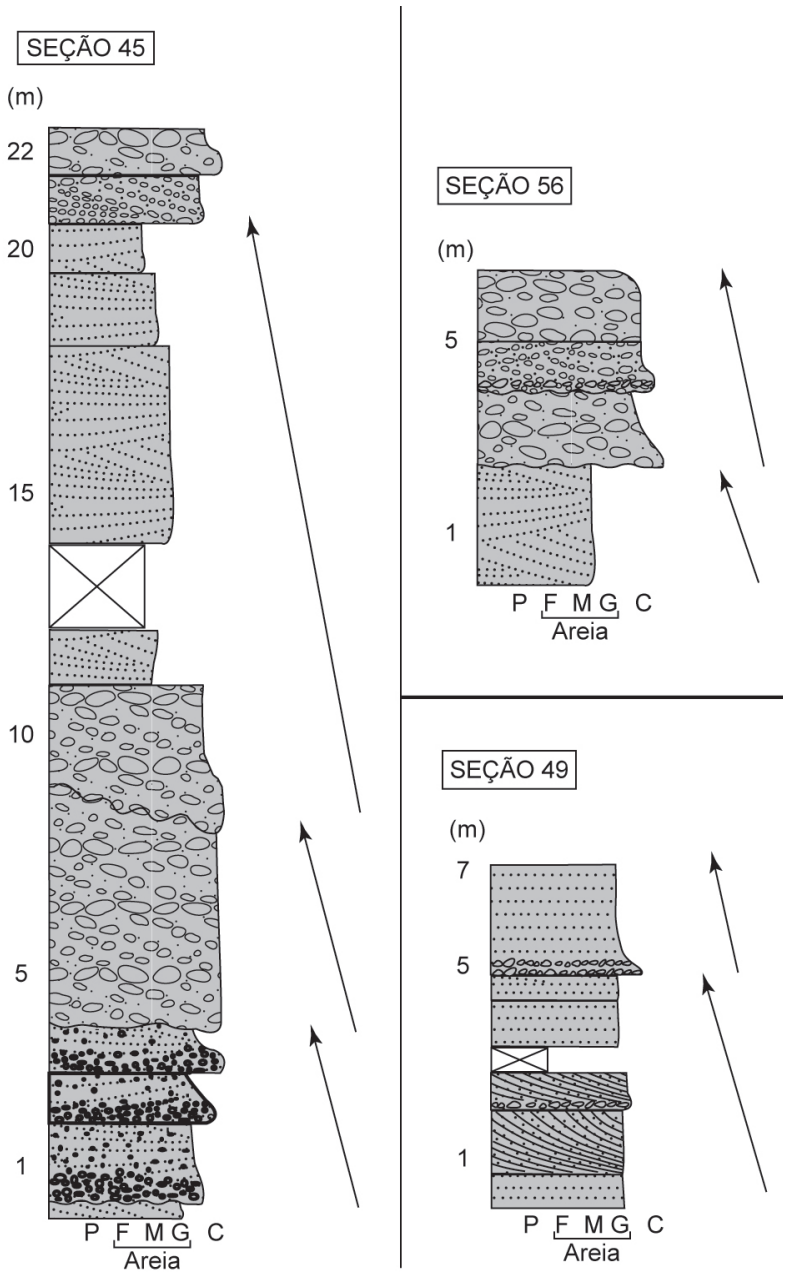

Figura 16 - Seções colunares das associações de fácies de canais fluviais efêmeros da sequência I com os ciclos granodecrescentes demarcados.

similares às da I (Fig. 18). O padrão de paleocorrentes também não apresenta mudanças quando comparado ao padrão da sequência I (Fig. 17).

Sequência III Alcança até $100 \mathrm{~m}$ de espessura. A discordância que marca o início desta sequência (LS3) foi verificada em dois afloramentos. $\mathrm{Na}$ 

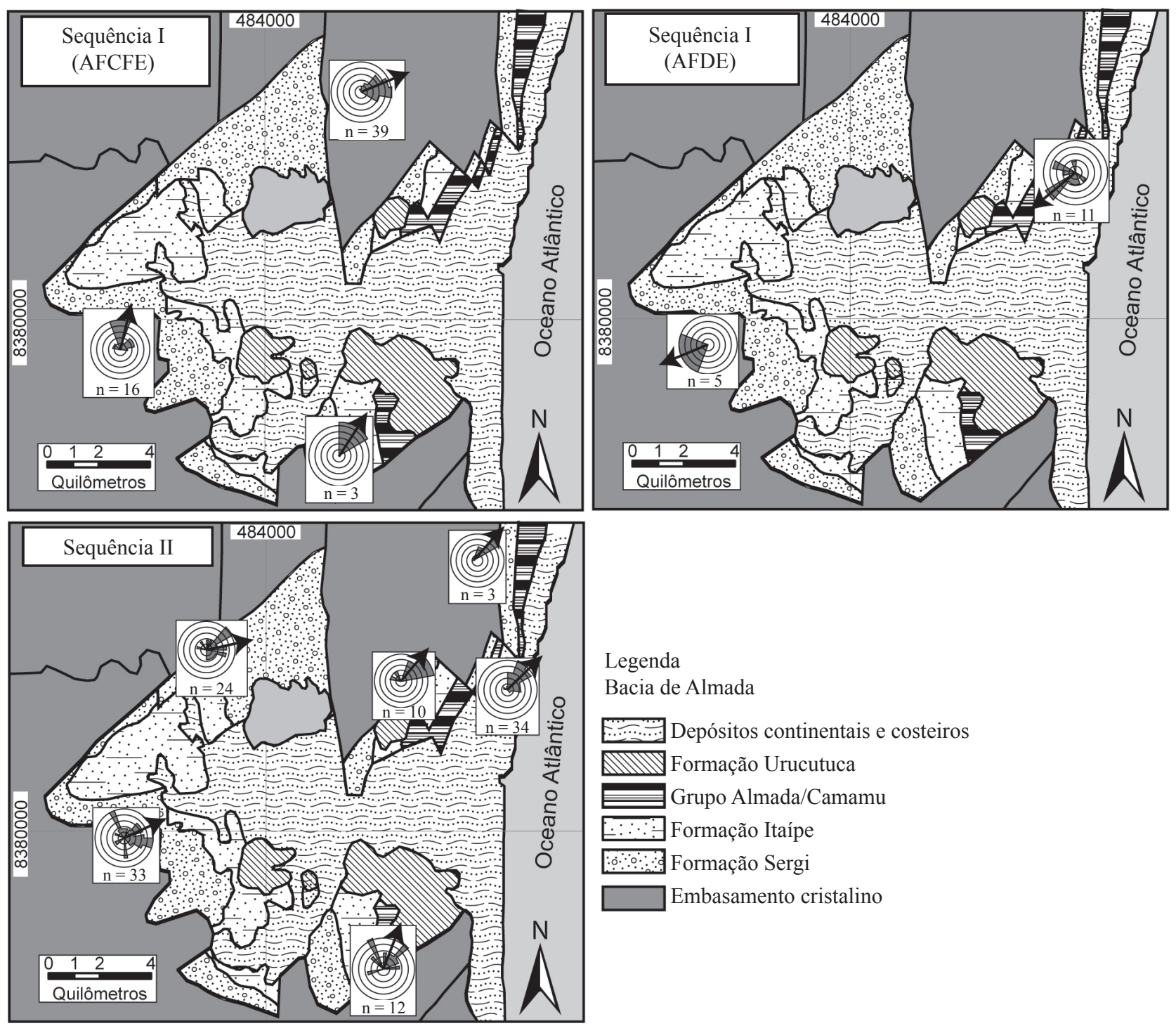

Legenda

Bacia de Almada

........... Depósitos continentais e costeiros

Formação Urucutuca

Ea Grupo Almada/Camamu

$\therefore$ Formação Itaípe

Formação Sergi

$\square$ Embasamento cristalino

Figura 17 - Mapas de paleocorrentes das sequências I e II.

porção sul da bacia, os depósitos fluviais da sequência II são sobrepostos por um pacote delgado de lençóis de areia eólicos que são cobertos por pelitos lacustres. Na porção norte, a mesma é sobreposta diretamente por depósitos lacustres (Fig. 9). Nos poços, esta superfície foi demarcada pelas mudanças de padrões observadas nas curvas de raios gama e DT (sônico), como visto na Fig. 12. As variações faciológicas mencionadas podem ser inferidas nos perfis dos poços, marcadas por um aumento nos valores de raios gama (depósitos lacustres) ou por uma mudança no padrão de tais raios (passagem de um padrão serrilhado - AFCFE - para um em caixote - AFLE), observado na Fig. 12.

O topo desta sequência não foi observado em campo, sendo definida em poços por discordância angular com os conglomerados das Formações Morro do Barro e Urucutuca (Fig. 13).

\section{EVOLUÇÃO SEDIMENTAR E FATORES CONTROLADORES Conforme discutido, os} depósitos flúvio-eólicos da Formação Sergi na Bacia de Almada podem ser individualizados em três sequências deposicionais distintas. A acumulação de sequências deposicionais continentais e o desenvolvimento de suas discordâncias limítrofes refletem o balanço entre as taxas de acomodação (A) e as de suprimento sedimentar (S) (Martinsen et al. 1999). Contextos em que a razão $\mathrm{A} / \mathrm{S}$ é maior que 1 são caracterizados por inundações lacustres, visto que o suprimento sedimentar não é suficiente para preencher o espaço de acomodação disponível. Por sua vez, se a razão A/S ficar entre 0 e 1 , o suprimento sedimentar preenche toda a acomodação criada com depósitos fluviais e/ou eólicos. Finalmente, quando a razão A/S é negativa, ocorre a erosão de sedimentos previamente depositados, resultando no desenvolvimento de uma discordância subaérea (limite de sequências). 




Figura 18 - Seções colunares da sequência II com os ciclos granodecrescentes indicados.

A sequência I marca o primeiro episódio deposicional da bacia, estando em contato direto com o embasamento cristalino. Para ocorrer agradação e consequente acumulação sedimentar, é necessária uma razão $\mathrm{A} / \mathrm{S}$ positiva. A dominância de depósitos fluviais e eólicos nesta unidade, sem o desenvolvimento dos lacustres, indica que, embora positiva, a razão A/S encontrava-se entre 0 e 1 . Internamente, esta mesma sequência apresenta uma sucessão estratigráfica bem definida, caracterizada por depósitos fluviais na base (AFCFE), seguida por estratos eólicos no topo (AFDE/ AFIE). Essa mudança nas características deposicionais deve estar associada a oscilações climáticas de longa duração, provavelmente relacionadas a ciclos orbitais (de Milankovitch). Estes ciclos climáticos são gerados como última consequência de mudanças na insolação terrestre. A atmosfera acomoda tais mudanças no aquecimento por meio do ajuste da distribuição das células de pressão atmosférica e dos padrões de circulação. Combinadas a estas mudanças, alteram-se os padrões de evaporação e precipitação (Perlmutter \& Azambuja Filho 2005). Períodos relativamente mais úmidos são caracterizados por 
um aumento da taxa de precipitação e pelo consequente aumento do escoamento de águas superficiais, favorecendo o desenvolvimento dos sistemas fluviais. Por outro lado, períodos áridos, além de reduzirem a atividade fluvial, aumentam a capacidade de transportar sedimentos eólicos, favorecendo a acumulação eólica (Kocurek 1988, Kocurek \& Havholm 1993).

Regionalmente, os depósitos fluviais e eólicos da sequência I representam as porções proximais a sul de um sistema desértico desenvolvido em uma ampla e contínua bacia endorreica (Küchle et al. 2011). A paleocorrente para NE da AFCFE indica que o sistema fluvial tinha como área-fonte o embasamento cristalino a SW (Küchle et al. 2011). O padrão de ventos marcado pelas paleocorrentes para SW das dunas eólicas é concordante ao modelo quantitativo de circulação atmosférica, desenvolvido por Scherer e Goldberg $(2007,2010)$. Tal modelo indica que um regime de ventos de monções predominava nas baixas latitudes do Gondwana durante o Jurássico Superior.

As sequências I e II são limitadas por discordância regional ocasionada por razão A/S negativa. A acumulação da sequência II foi associada com uma nova subida no nível de base estratigráfico, resultando em uma razão A/S positiva. Essa unidade foi depositada dentro de uma ampla planície aluvial, caracterizada por cinturões de canais entrelaçados com paleocorrente para NE. A dominância dos corpos arenosos de canais fluviais amalgamados, sem a preservação dos depósitos de planície de inundação, indica baixa taxa de criação de acomodação, com razão A/S positiva, mas próxima a zero (Miall 1996, Martinsen et al. 1999).

A passagem da sequência I para a II representa mudanças climáticas para condições mais úmidas. Neste estágio, a capacidade fluvial do transporte de sedimentos aumenta novamente, possibilitando a reinstalação de um sistema fluvial. Por meio da análise de paleocorrentes em bacias adjacentes (Recôncavo, Tucano, Sergipe-Alagoas e Gabão) e correlação em perfis gama, sugere-se que a LS2 corresponda também a uma reorganização tectônica da bacia em escala regional (Küchle et al. 2011). Durante este rearranjo tectônico, desenvolvem-se altos estruturais internos à bacia que causam o redirecionamento das drenagens existentes, consequentemente alterando os padrões de paleocorrentes nas porções distais do sistema aluvial.
Como a Bacia de Almada representa a porção mais proximal a sul desta grande bacia, as paleocorrentes não apresentam mudanças significativas em relação à sequência I. Sendo assim, o que anteriormente era uma ampla e contínua bacia endorreica com padrão centrípeto de drenagens, passa a ser uma com altos estruturais internos que definem depocentros isolados, embora ainda com uma grande extensão lateral (Küchle et al. 2011).

A sequência III é limitada na base por uma discordância regional que marca um novo evento de razão A/S negativa. Esta, diferentemente das sequências I e II, não possui a mesma uniformidade lateral das associações de fácies ao longo da Bacia de Almada. Nas áreas ao sul da bacia, desenvolvem-se lençóis de areia eólicos sobrepostos às fácies fluviais da sequência II. Já nas regiões a NE da bacia, fácies lacustres ocorrem em contato direto com a sequência II.

A partir dessas observações, assume-se que a sequência III tenha sido depositada sob um regime de subsidência diferencial, associado a um rearranjo interno dos depocentros da bacia, possivelmente seguindo uma tendência tectônica regional iniciada na sequência III. Nessas condições, o espaço de acomodação gerado é heterogêneo ao longo da bacia, promovendo o desenvolvimento de diferentes associações de fácies em áreas mais restritas. Além disso, a taxa de criação do espaço de acomodação é maior (razão A/S maior que 1), possibilitando o desenvolvimento de ambientes lacustres. Segundo Kuchle et al. (2011), este afogamento lacustre tem uma expressão regional, podendo ser observado nas bacias de Camamu e Recôncavo e marcando o início do estágio de desenvolvimento de meios grábens, que compartimentou definitivamente a ampla sinéclise existente na sequência I e, em menor extensão, na II. Este estágio tectônico foi denominado por Kuchle et al. (2011) como trato tectônico de desenvolvimento de meio gráben, enquanto a fase de sinéclise, na qual foram acumuladas as sequências I e II, configura o trato tectônico de início de rifte.

\section{CONCLUSÕES A Formação Sergi na Bacia} de Almada pode ser subdividida em três sequências deposicionais geneticamente relacionadas. As sequências I e II correspondem ao intervalo litoestratigráfico da Formação Sergi e a III abrange o topo da Formação Sergi mais a Formação Itaípe. Esta 
divisão faz parte de um arcabouço definido regionalmente para diversas bacias do nordeste brasileiro e da África.

A Sequência I possui entre 40 e $70 \mathrm{~m}$ de espessura, sendo composta pelas AFCFE, AFDE e AFIE. Os depósitos de canais fluviais formam complexos amalgamados multilaterais e multiepisódicos e são preenchidos por sucessões com granodecrescência ascendente. As litofácies presentes são: Gt, Gh, G, $\mathrm{St}$, Sl e Sh. As paleocorrentes medidas na AFCFE indicam paleofluxos dos canais para o quadrante NE. A AFDE é formada por arenitos finos a médios, dispostos em sets de estratificação cruzada acanalada com até $4 \mathrm{~m}$ de espessura. Os estratos cruzados são formados por depósitos de fluxo de grãos e por laminações de marcas onduladas eólicas. A AFIE é composta por arenitos finos a médios com estratificação plano-paralela, formada exclusivamente por laminações de marcas onduladas eólicas. A paleocorrente medida nos estratos cruzados eólicos indica a migração das paleodunas para o quadrante SW.

A sequência II possui de 15 a $45 \mathrm{~m}$ de espessura, sendo formada exclusivamente pela AFCFE. A arquitetura deposicional é semelhante à da sequência 1 , com corpos arenosos formando complexos amalgamados multilaterais e multiepisódicos. Estes corpos, interpretados como depósitos de canais fluviais, são preenchidos por ciclos granodecrescentes compostos pelas litofácies Gt, Gh, Gm, St, Sh, Sl e Sm. A paleocorrente obtida nesta sequência indica um paleofluxo de tais canais para NE.

A passagem da sequência I para a II marca um rearranjo tectônico em escala regional, definido por correlações realizadas em diversas bacias do nordeste brasileiro. Nesta fase, o que anteriormente era uma ampla e contínua bacia endorreica com padrão centrípeto de drenagens, passa a ser uma com altos estruturais internos que definem depocentros isolados, embora ainda com uma grande extensão lateral.

A sequência III possui até $100 \mathrm{~m}$ de espessura e é formada por associações de fácies de lençóis de areia eólicos e lacustre. Os depósitos eólicos estão contidos em um delgado pacote de arenito médio com estratificação cruzada de baixo ângulo. As estratificações são compostas essencialmente por laminações de marcas onduladas eólicas. Na porção sul da bacia, tais lençóis de areia eólicos são sobrepostos pela associação de fácies lacustre. Já na porção norte, os depósitos fluviais da sequência II são cobertos diretamente por depósitos lacustres.

A partir da sequência III interpreta-se que o regime de subsidência passe a ser diferencial ao longo da Bacia de Almada. Neste intervalo, formam-se depocentros isolados dentro dela que causam uma distribuição mais restrita das associações de fácies. Adicionalmente, o espaço de acomodação gerado é maior, possibilitando a formação de ambientes lacustres. Regionalmente, esse estágio é interpretado como o início da formação de meios grábens (trato tectônico de desenvolvimento de meio gráben).

\section{AGRADECIMENTOS À Petrobras pelo} financiamento do projeto de pesquisa que originou este estudo. À Agência Nacional do Petróleo, Gás Natural e Biocombustíveis (ANP) por ceder os poços utilizados neste trabalho. Ao Instituto de Geociências da Universidade Federal do Rio Grande do Sul (UFRGS) pela infraestrutura e pelos recursos humanos disponibilizados ao longo da execução deste artigo. Finalmente, à equipe do Projeto Rifte pelas grandes discussões e apoio durante as etapas de campo e laboratório.

\section{Referências}

Bongiolo D.E. \& Scherer C.M.S. 2010. Facies architecture and heterogeneity of the fluvial-aeolian reservoirs of the Sergi formation (Upper Jurassic), Recôncavo Basin, NE Brazil. Marine and Petroleum Geology, 27(9):1885-1897.

Carvalho K.W.B. 1965. Geologia da Bacia Sedimentar do Rio Almada. Boletim Técnico da Petrobrás, 8(1):5-55.

Chang H.K. \& Kowsmann R.O. 1987. Interpretação genética das seqüências estratigráficas das Bacias da Margem Continental Brasileira. Revista Brasileira de Geociências, 17(2):74-80.
Dias K.D.N. \& Scherer C.M.S. 2008. Cross-bedding set thickness and stratigraphic architecture of aeolian systems: An example from the Upper Permian Pirambóia Formation (Paraná Basin), southern Brazil. Journal of South American Earth Sciences, 25:405-415.

Hirst J.P.P. 1991. Variations in alluvial architecture across the Oligo-Miocene Huesca fluvial system, Ebro Basin, Spain. In: Miall A.D. \& Tyler N. (eds.) The three dimensional facies architecture of terrigenous clastic sediments and its implications for hydrocarbon discovery and recovery. Society of Economic 
Paleontologists and Mineralogists, 3, Concepts in Sedimentology and Paleontology, p. 11-21.

Hunter R.E. 1977. Basic types of stratification in small eolian dunes. Sedimentology, 24:361-387.

Kocurek G. 1988. First-order and super bounding surfaces in eolian sequences - Bounding surfaces revisited. Sedimentary Geology, 56(1):193-206.

Kocurek G. \& Havholm K.G. 1993. Eolian sequence stratigraphy - a conceptual framework. In: Weimer P. \& Posamentier H.W. (eds.) Siliciclastic sequence stratigraphy: recent developments and applications, 52, Society of Economic Paleontologists and Mineralogists, p. 393-409.

Küchle J., Scherer C.M.S., Born C.C., Adegas F. 2011. A contribution to regional stratigraphic correlations of the Afro-Brazilian depression - The Dom João Stage (Brotas Group and equivalent units - Late Jurassic) in Northeastern Brazilian sedimentary basins. Journal of South American Earth Sciences, 31:358-371.

Martinsen O.J., Ryseth A., Helland-Hansen W., Flesche H., Torkildsen G., Idil S. 1999. Stratigraphic base level and fluvial architecture: Ericson Sandstone (Campanian), Rock Springs Uplift, SW Wyoming, USA. Sedimentology, 46:235- 259.

Miall A.D. 2006. The geology of fluvial deposits: sedimentary facies, basin analysis and petroleum geology: Springer-Verlag Inc., Heidelberg, 582 p.

Miall A.D. 1996. The Geology of Fluvial Deposits: Sedimentary Facies, Basin Analysis and Petroleum Geology. New York, Springer-Verlag, 582 p.

Mountney N.P. 2006. Periodic accumulation and destruction of aeolian erg sequence in the Permian Cedar Mesa Sandstone, White Canyon, southern Utah, USA. Sedimentology, 53(4):789-823.

Mountney N.P. \& Thompson D.B. 2002. Stratigraphic evolution and preservation of eolian dune and damp/wet interdune strata: an example from Triassic Helsby Sandstone Formation, Chesshire Basin, UK. Sedimentology, 49: 805-834.

Netto A.S.T. \& Sanches C.P. 1991. Roteiro geológico da bacia do Almada, Bahia. Revista Brasileira de Geociências, 21(2):186-198.
Ojeda H.A.O. 1983. Estrutura e evolução das Bacias Mesozóicas Emersas da Margem Continental Brasileira. Revista Brasileira de Geociências, 13(2):71-83.

Oliveira F.M. 2005. Análise estratigráfica da Formação Sergi, Campo de Fazenda Bálsamo, Bacia do Recôncavo, Bahia. Dissertação de Mestrado, Instituto de Geociências, Universidade Federal do Rio Grande do Sul, 172 p.

Perlmutter M.A. \& Azambuja Filho N.C. 2005. Cicloestratigrafia: teoria e técnicas. Revista Brasileira de Geociências, 35:1-12.

Pierini C., Mizusaki A.M., Pimentel N., Faccini U.F., Scherer C.M.S. 2010. Paleoweathering features in the Sergi Formation (Jurassic - Cretaceous), northeastern Brazil, and implications for hydrocarbon exploration. Journal of South American Earth Sciences, 29:412-426.

Scherer C.M.S \& Goldberg K. 2010. Cyclic cross-bedding in the eolian dunes of the Sergi Formation (Upper Jurassic), Recôncavo Basin: Inferences about the wind regime. Palaeogeography, Palaeoclimatology and Palaeoecology, 296:103-110.

Scherer C.M.S \& Goldberg K. 2007. Palaeowind patterns during the latest Jurassic earliest Cretaceous in Gondwana: evidence from aeolian cross-strata of the Botucatu formation, Brazil. Palaeogeography, Palaeoclimatology, Palaeoecology, 250:89-100.

Scherer C.M.S. \& De Ros L.F. 2009. Heterogeneidades dos reservatórios flúvio-eólicos da Formação Sergi na Bacia do Recôncavo. Boletim de Geociências da PETROBRAS (Impresso), 17:249-271.

Scherer C.M.S., Lavina E.L.C., Filho D.C.D., Oliveira F.M., Bongiolo D.E., Aguiar E.S. 2007. Stratigraphy and facies architecture of the fluvial-aeolian-lacustrine Sergi Formation (Upper Jurassic), Recôncavo Basin, Brazil. Sedimentary Geology, 194(3-4):169-193.

Spalletti L.A. \& Piñol F.C. 2005. From Alluvial Fan to Playa: An Upper Jurassic Ephemeral Fluvial System, Neuquén Basin, Argentina. Gondwana Research, 8(3):363-383.

Manuscrito ID 22729

Recebido em: 24/08/2011

Aprovado em: 24/09/2012 